\title{
Inflation Differentials in the EU: \\ A Common (Factors) Approach with \\ Implications for EU8 \\ Euro Adoption Prospects
}

\author{
Nada Choueiri, Franziska Ohnsorge, and \\ Rachel van Elkan
}





\title{
IMF Working Paper
}

European Department

Inflation Differentials in the EU:

A Common (Factors) Approach with Implications for EU8 Euro Adoption Prospects

\author{
Prepared by Nada Choueiri, Franziska Ohnsorge, and Rachel van Elkan ${ }^{1}$ \\ Authorized for distribution by Michael Deppler
}

January 2008

\begin{abstract}
This Working Paper should not be reported as representing the views of the IMF. The views expressed in this Working Paper are those of the author(s) and do not necessarily represent those of the IMF or IMF policy. Working Papers describe research in progress by the author(s) and are published to elicit comments and to further debate.
\end{abstract}

This paper explores inflation determinants within the EU and implications for new members' euro adoption plans. Factor analysis partitions observed inflation in EU25 countries into common-origin and country-specific (idiosyncratic) components. Cross-country differences in common-origin inflation within the EU are found to depend on gaps in the initial price level, changes in the nominal effective exchange rate, the quality of institutions, and the economy's flexibility. Idiosyncratic inflation is generally small in magnitude. Nonetheless, the results show that country-specific shocks have systematically pushed down headline inflation, potentially influencing the assessment of compliance with the Maastricht inflation criterion.

JEL Classification Numbers:C13; C33; E31; F15

Keywords:Inflation; generalized dynamic factors model; euro adoption Author's E-Mail Address:rvanelkan@,imf.org, nchoueiri@imf.org, fohnsorge@,imf.org.

\footnotetext{
${ }^{1}$ We thank Emil Stavrev for his contribution as a coauthor at an early stage in this project. We also thank Haiyan Shi for outstanding reasearch assistance, and Kexue Liu for excellent support with MATLAB programming.
} 


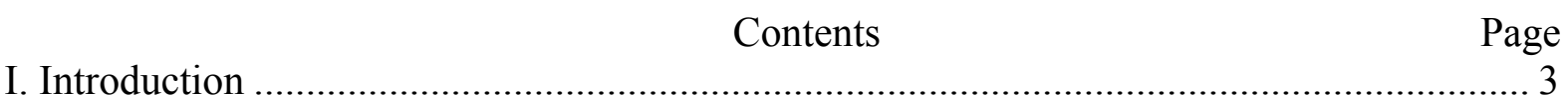

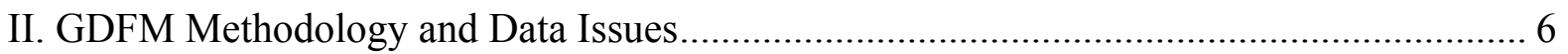

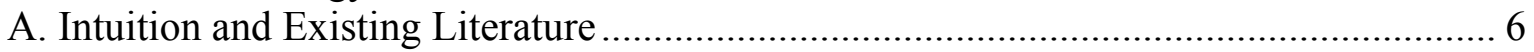

B. GDFM Statistical Framework for Common-Origin Inflation ........................................ 7

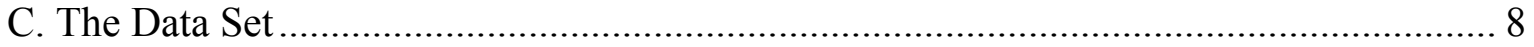

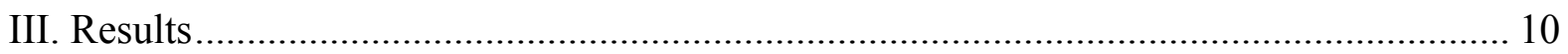

A. Covariance Properties and Number of Common Factors .......................................... 10

B. Common-Origin Inflation in the 25 EU Countries......................................................... 11

C. Explaining Intra-EU Common-Origin Inflation Differentials ...................................... 15

D. Idiosyncratic Inflation and the Maastricht Criterion.................................................... 22

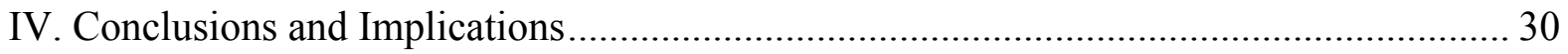

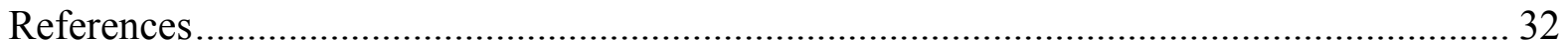

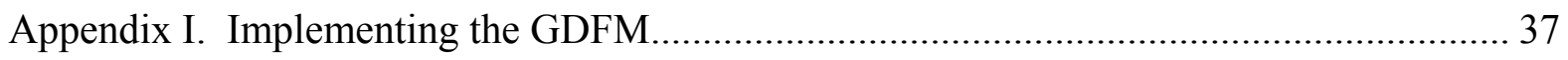

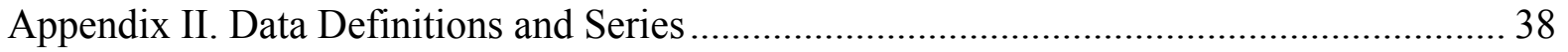




\section{INTRODUCTION}

Countries joining the European Union (EU) during recent enlargements are eventually required to adopt the euro. ${ }^{2}$ To do so, inflation must be brought down close to rates prevailing in low-inflation EU countries, as specified in the Maastricht inflation criterion. ${ }^{3}$ This requirement has been interpreted as allowing entry only to countries that demonstrate a preference for low inflation and maintain institutions to support this outcome - that is, they display a "stability culture.", The eight Central and Eastern European countries that acceded to the EU in 2004 (EU8) had seen low or declining inflation over the previous decade. Slovenia satisfied the criterion in 2006 and entered the euro area at the beginning of 2007. Most of the other EU8 aim to adopt the single currency within the next three-to-five years, while even those on a slower track plan to join the euro area before the middle of the next decade. Do these countries have the wherewithal to achieve sufficiently low inflation to satisfy their euro adoption goals, or will structural or other factors impede their plans?

To shed light on the euro entry prospects of the EU8, this paper explores the determinants of inflation in the 25 countries of the pre-2007 EU (EU25). While globalization and technological advances have helped depress inflation levels worldwide (IMF, 2006), intraEU economic integration has been a strong force toward inflation convergence within this country group. The starting premise is that each countries' headline inflation is a composite of factors affecting all countries within the EU (common-origin inflation), in addition to idiosyncratic, country-specific elements. Common-origin inflation may reflect EU-centric factors, as well as those with a broader country reach. Underlying this decomposition is the fact that business cycle synchronization within the euro area and between new and old EU members has increased in recent years. ${ }^{5}$ Moreover, strong trade links facilitated by the EU's single market for goods and capital has allowed price signals to be more readily transmitted between EU members. In this framework, the influence of common shocks on inflation is a function of individual countries' structural and institutional characteristics. Using indicators of ongoing structural convergence, and macroeconomic and institutional variables, the paper investigates empirically the sources of cross-country differences in common-origin inflation

\footnotetext{
2 The May 2004 enlargement saw the entry of ten new members (Cyprus, the Czech Republic, Estonia, Hungary, Latvia, Lithuania, Malta, Poland, Slovenia, and the Slovak Republic). Two additional countries, Bulgaria and Romania, entered in January 2007.

${ }^{3}$ The inflation criterion stipulates that year-average inflation in the candidate country may not exceed by more than $1 \frac{1}{2}$ percentage points the average of the inflation rates of the "three best-performing member states in terms of price stability."

${ }^{4}$ See De Grauwe (2003) and Morales and Padilla (1994) for the motivation for the design of the Maastricht criteria, and Bofinger (1992), Collins and Giavazzi (1993), Hayo (1997), and Issing (2006) for a discussion of the importance of public attitudes toward inflation to inflation outcomes.

${ }^{5}$ Bower and Guillemineau (2006), De Grauwe and Mongelli (2005), Boreiko (2002), and Fidrmuc and Korhonen (2004).
} 
within the EU. Also, the influence of idiosyncratic inflation on a country's ability to meet the Maastricht inflation criterion is analyzed. Specifically, the effect of idiosyncratic inflation on the level of the inflation criterion, as well as on the choice of countries that determines the criterion, is examined.

This paper represents a synthesis of several strands of the literature. First, to decompose inflation into common-origin and idiosyncratic components, the paper applies dynamic factor analysis to inflation rates in the 25 countries of the EU. Similar models have recently been used to study inflation dynamics in the euro area. For the euro area aggregate, Hahn (2002), Cristadoro and others (2005), and Stavrev (2006) use a generalized dynamic factor model (GDFM) to construct a measure of core inflation. De Simone (2005) applies a GDFM to obtain common-origin inflation for individual euro area countries, where the ECB's single monetary policy is viewed as the channel transmitting common shocks within the monetary union.

This paper also builds on the extensive literature on the origin and size of headline inflation differentials within the euro area and the EU15. This work was motivated by an attempt to understand how the ECB's common monetary policy has influenced inflation heterogeneity within the union, and the limits to euro area inflation convergence. ${ }^{6}$ Previous studies have found that, while differentials in headline inflation within the EU15 have narrowed since the early 1990s, important temporary and more persistent sources of heterogeneity remain. Headline inflation differentials are found to have decreased on account of ERM participation (Busetti and others, 2006), greater product market competition (Przbyla and Roma, 2005), and membership in the single market (De Grauwe and Mongelli, 2005). However, countryspecific factors - whether policies, shocks, or more durable structural causes - are deemed to have precluded full inflation convergence. These factors include misaligned business cycles, differences in trade openness and oil dependency, productivity and income differentials, gradual price level harmonization, and differences in wage and price rigidities. ${ }^{7}$ In fact, Busetti and others (2006) find that after considerable convergence in the run-up to the inception of the euro, euro area inflation rates have since diverged, with two distinct groups coexisting: a low-inflation group with rates of 1.3-1.8 percent, and a higher-inflation group with rates between 3.1 and 3.7 percent.

This paper also draws on the literature linking the institutional setting to inflation outcomes. Inflation, as well as income growth, has been shown to depend on the quality of institutions, lending support to a stability culture as an important moderator of inflation. Key institutions

\footnotetext{
${ }^{6}$ In the euro area, where nominal exchange rates are fixed across member countries, differences in inflation rates are the primary vehicle for achieving equilibrating changes in real exchange rates (Westaway, 2003).

${ }^{7}$ See, for example, Angeloni and Ehrmann (2004), Assenmacher-Wesche and Gerlach (2006), Buiter (2005), ECB (2003), European Commission (2000), Honohan and Lane (2003), and Lane (2006). However, BalassaSamuelson effects are found to be of limited empirical importance in explaining inflation differentials (Altissimo, Benigno, and Palenzuela, 2005; and Mihaljek, 2002)).
} 
for inflation performance are determined to be central bank independence, which is negatively correlated with inflation, and trade union density, which is positively linked to inflation (with a possible hump shape) ${ }^{8}$ In addition, greater political instability is found to be correlated with higher inflation, but only in the case of developing countries, ${ }^{9}$ while there is some evidence that the quality of fiscal institutions affects the size and cyclicality of budget outcomes, providing a possible indirect link to inflation. ${ }^{10}$

This paper has three objectives. First, it seeks to decompose inflation in each of the $25 \mathrm{EU}$ countries into a common-origin component and an idiosyncratic component using the GDFM approach. This approach is operationalized by extracting common signals from a very large number of price and nonprice time series for the 25 countries. The inclusion of nonprice variables allows signal extraction from real, financial, and currency market variables that hold information on prices, including through real business cycles and Phillips curve relationships. The common-origin component of inflation is that part driven by shocks affecting all EU25 countries. This component may nonetheless differ across countries because country-specific characteristics affect the way in which shocks impact the real economy. The paper's second objective is therefore to explore the determinants of crosscountry differences in the common-origin component of inflation. It examines the potential roles of income and price convergence, macroeconomic variables (including nominal effective exchange rate changes and openness), and institutional indicators that embody the concept of a stability culture (size of government, political stability, legal system effectiveness, and extent of labor and product market flexibility) in inflation heterogeneity. And third, the paper aims to assess the effect of idiosyncratic inflation on the calculated Maastricht reference rate.

The GDFM results indicate that common shocks account for a roughly similar share of inflation variability in the EU15 and the EU8, supporting the inclusion of all 25 countries in the sample. Each country's common-origin component of inflation is shown to track quite closely broad trends in its headline inflation, but deviations are nonetheless sizable on occasion. Moreover, common shocks account for a larger share of the variability in headline inflation in countries that are more open to external trade. Cross-country differences in the common-origin component of inflation across the EU25 are found to reflect different initial price levels and the behavior of nominal effective exchange rates. Institutions are also found to be an important determinant of inflation heterogeneity, with labor market flexibility and legal system effectiveness accounting for a sizable amount of cross-country heterogeneity.

\footnotetext{
${ }^{8}$ See Rogoff (1985), Cukierman (1992), Alesina and Summers (1993), Cukierman and Lippi (1999), Bowdler and Nunziata (2006), and International Monetary Fund (2006).

${ }^{9}$ Aisen and Viega (2006). Cukierman, Edwards, and Tabellini (1992) postulate that political instability and polarization affect inflation by reducing the efficiency of the tax system, and by inducing greater recourse to revenues from seignorage.

${ }^{10}$ Fabrizio and Mody (2006) and EC (2006).
} 
The presence of - at times sizable - idiosyncratic inflation is shown to have pushed down the Maastricht inflation criterion, including through a selection bias, whereby countries with the lowest headline inflation are systematically found to have had negative idiosyncratic shocks that qualified them as low-inflation countries. Moreover, favorable country-specific shocks are found to have enabled one current euro member to pass the inflation hurdle in qualifying for euro adoption. Among the non-euro EU8, the inertial convergence process could keep inflation differences elevated for several more years, although high institutional quality will help offset this by promoting flexible responses to shocks.

\section{GDFM METHODOLOGY AND DATA ISSUES}

This section presents the intuition and discusses the application of factor models to macroeconomic issues, specifically, inflation. It then outlines the statistical framework and key assumptions that are needed to estimate the GDFM.

\section{A. Intuition and Existing Literature}

This paper adopts the GDFM developed by Forni and others (1999) and Forni and Lippi (2001) to estimate the common-origin component of inflation in the $25 \mathrm{EU}$ countries. The GDFM is a generalization of dynamic factor models (DFMs) that were first applied to macroeconomic data in the late 1970 s, but which required strong restrictions on the correlations among the variables. ${ }^{11}$ The premise of factor analysis is that covariation among a large number of time series can be traced to a few unobserved shocks, or "factors," although the impact of these shocks - and therefore each series' common-origin component — may vary.

Factor models are well suited to macroeconomic data because many series display considerable comovement, suggesting the presence of one or more unobserved driving forces. In fact, early applications of DFMs to macroeconomics (Geweke, 1977; Sargent and Sims, 1977; Stock and Watson, 1989 and 1991; and Sargent, 1987) found that only a handful of such factors are needed to account for the variation and covariation in many major macroeconomic time series. These latent factors can be interpreted as shared or common demand-and-supply shocks. In essence, factor models transform large numbers of covarying series into a smaller number of orthogonal series (sequences of common factors) in such a way that each successive factor explains as much as possible of the remaining variation in the observed series. These observed series can therefore be written as the weighted sum of the common factors (the common-origin component), plus an idiosyncratic disturbance term, which is uncorrelated with the common-origin component and, hence, is series specific.

\footnotetext{
${ }^{11}$ The GDFM thereby differs from the DFM by relaxing the assumption of mutually orthogonal idiosyncratic components, allowing some mild cross-correlations. See Reichlin (2002) for details. The term "dynamic" in DFM refers to the property that common factors need not be loaded contemporaneously, i.e., their impact on different series can occur with different lags.
} 
An appealing property of DFMs is that they can accommodate data sets with very large cross-section and time-series dimensions, allowing information to be extracted from a rich data base. In this paper, the analysis employs about 3,400 time series, something that would be well beyond the scope of standard estimation techniques, which rely on the assumption that the number of time-series observations greatly exceeds the cross-section dimension. ${ }^{12}$ Such huge data sets are accommodated within DFMs by reducing the dimensionality of the data through parsimonious parameterization. Moreover, enlarging the dataset in a DFM actually improves identification because additional series help pin down more precisely the common shocks, provided the idiosyncratic disturbances diminish in the aggregate. DFMs are therefore seen to "turn dimensionality from a curse into a blessing" (Stock and Watson, 2006).

As noted previously, several authors have recently applied GDFMs to the study of core inflation in the euro area. The resulting inflation indicators are seen as improving on traditional measures of core inflation, which are constructed in two possible ways: first, using disaggregated price data to remove idiosyncratic and transient shocks through the exclusion of volatile energy and food series or by eliminating statistical outliers through trimmed-mean estimates (Bryan and Cecchetti, 1997); or second, combining data on aggregate prices and real activity to obtain a structural measure of inflation (Quah and Vahey, 1995). Using both disaggregated price and nonprice data, the GDFM core inflation measure delivers the benefits of both approaches, while avoiding the need to exclude relevant data series because of dimensionality constraints. The resulting common-origin euro area inflation measure can be interpreted as the Harmonized Index of Consumer Price (HICP) inflation cleansed of idiosyncratic shocks. ${ }^{13} 14$

\section{B. GDFM Statistical Framework for Common-Origin Inflation}

This section provides the basic equations and assumptions of the GDFM. Appendix I gives an informal overview of the estimation technique. For a more systematic and rigorous treatment, the reader is referred to Altissimo and others (2001).

\footnotetext{
${ }^{12}$ For example, ordinary least squares (OLS) estimators are consistent only under the assumption that $N / T$ (where $N$ is the number of time series and $T$ the number of observations) converges asymptotically to zero.

${ }^{13}$ Depending on the composition of the data set, idiosyncratic components reflect country- and/or sectorspecific shocks, in addition to measurement error.

${ }^{14}$ In a second step, Cristadoro and others (2005) and Hahn (2002) smooth over the time-series dimension to eliminate volatile, high-frequency movements. In doing so, they obtain as their measure of core inflation the medium- and long-run common-origin component. With relatively long monetary policy transmission lags that make it inappropriate to react to transitory shocks, long-term common-origin inflation is seen as most relevant for policymakers.
} 
As in traditional DFMs, at any time, $t$, each variable, $\mathrm{x}_{j t}$, can be represented as the sum of two mutually orthogonal unobservable components: the common-origin component, $\chi_{j t}$, and the idiosyncratic component, $\zeta_{j t}$. The common-origin component is driven by a small number, $q$, of common factors or shocks, $\mu_{h t}, h=1, \ldots, q$, which are the same for all the cross section, but possibly loaded with different coefficients and/or lag structures for each $\mathrm{x}_{j}$. By contrast, the idiosyncratic component is driven by variable-specific shocks. Hence, the observed series, $\mathrm{x}_{\mathrm{jt}}$, can be written as the sum of the common-origin component $\chi_{j t}$ and the idiosyncratic component, $\zeta_{j t}$. In turn, the common-origin component can be expressed as a finite moving average with maximum lag order $s$ of the $q$ common shocks:

$$
\begin{aligned}
\mathrm{X}_{\mathrm{jt}}=\chi_{j t}+\zeta_{j t}= & \mathbf{b}_{j}(\mathrm{~L}) \boldsymbol{\mu}_{t}+\zeta_{j t} \\
& =\sum_{h=1}^{q} \sum_{k=0}^{s} b_{j h k} \mu_{h, t-k}+\zeta_{j t},
\end{aligned}
$$

where $\boldsymbol{\mu}_{\mathrm{t}}$ and $\zeta_{\mathrm{t}}$ are mean zero, $\boldsymbol{\mu}_{t}$ has unitary variance, and $\zeta_{j t} \perp \mu_{h, t-k}$ for all $j, h, t$, and $k$.

These assumptions imply that covariation among the observed x's is due entirely to the effect of $q$ common latent factors, while variation in an individual variable, $\mathrm{x}_{j t}$, is due to the variation of the specific variable, $\zeta_{j t}$, as well as the variation and covariation of the common factor. Notice that the weights or factor loadings, $b_{j h k}$, are not dated, but specific to each variable $j$, common shock $h$, and lag $k$. Moreover, the reaction of each variable to a given common shock may be contemporaneous or lagged.

Additional assumptions, detailed in Forni and others (1999), are needed to distinguish the idiosyncratic from the common-origin component when the traditional orthogonality assumption of the DFM is relaxed. In general terms, these assumptions require total cross correlations to be small for the idiosyncratic components and large for the common-origin components. $^{15}$

\section{The Data Set}

The heterogeneous data set encompasses 3,344 variables (Table 1) and covers the pre-2007 25 EU member countries. About 65 percent of the series represent disaggregated HICP data, primarily at the four-digit level. Where HICP four-digit data are not available, they are replaced with prices at the next highest level of aggregation. Non-HICP data for the 25

\footnotetext{
${ }^{15}$ The assumptions imply restrictions on the magnitude of the eigenvalues of the spectral density matrices (the spectral-domain analog of time-series covariance matrices) of the common and idiosyncratic components so that each $\mu_{h t}$ is present in infinitely many cross-sectional units, while the effects of individual $\zeta$ 's are concentrated in a finite number of series.
} 
individual countries are also included, specifically, producer prices, industrial production, unemployment rates, interest rates, nominal effective exchange rates, the monetary aggregate M1, and private sector credit. In addition, variables relevant to a broader group of countries are also included (world oil prices, the euro area nominal effective exchange rate, and euro interest rates). Most data are downloaded from Eurostat. The data are of monthly frequency. To comply with the assumptions of the GDFM, several data transformations are performed. All variables except interest rates and unemployment rates - which remain in percent - are seasonally adjusted using the EViews' X12 procedure. To achieve stationarity, these data are $\log$ differenced. However, owing to the very large data set, this property was not verified ex post. Finally, the data are standardized by subtracting their means and dividing by their standard deviations. The latter transformation ensures that high-variance series do not dominate the results.

Table 1. Variables Included in the GDFM

\begin{tabular}{lr}
\hline Variable & Number of series \\
\hline HICP & 2259 \\
Industrial production & 533 \\
Long-term nominal interest rate & 24 \\
Short-term nominal interest rate & 13 \\
M1 & 10 \\
Nominal effective exchange rate & 23 \\
Oil price & 1 \\
PPI & 497 \\
Unemployment rate & 21 \\
Growth rate of credit to private sector & 22 \\
Nominal effective exchange rate of euro & 1 \\
& \\
Total & 3,344 \\
\hline
\end{tabular}

Detailed HICP data are available from December 1995 onward for the EU15, but only more recently for the EU8. As a result, the GDFM is performed on the full 25-country data set for the period January 2001 to December 2005. For the EU15, a longer time period is also considered (January 1996 to December 2005). 


\section{RESUlts}

\section{A. Covariance Properties and Number of Common Factors}

In the first step of the GDFM, the number of common factors is determined. This is done through a principal component analysis (PCA) of the spectral density matrices of the data. The results are summarized in Figures 1 and 2, which show the eigenvalues - individually and cumulatively, ordered by size-from the PCA over the range $[0, \pi] .{ }^{16}$ These eigenvalues indicate the share of the variance of the data explained by each successive principal component. It is apparent that, with the exception of the first eigenvalue, individual eigenvalues are quite smooth across all frequencies,

Figure 1. Share of Data Variability Explained by the First Ten Common Factors 1/

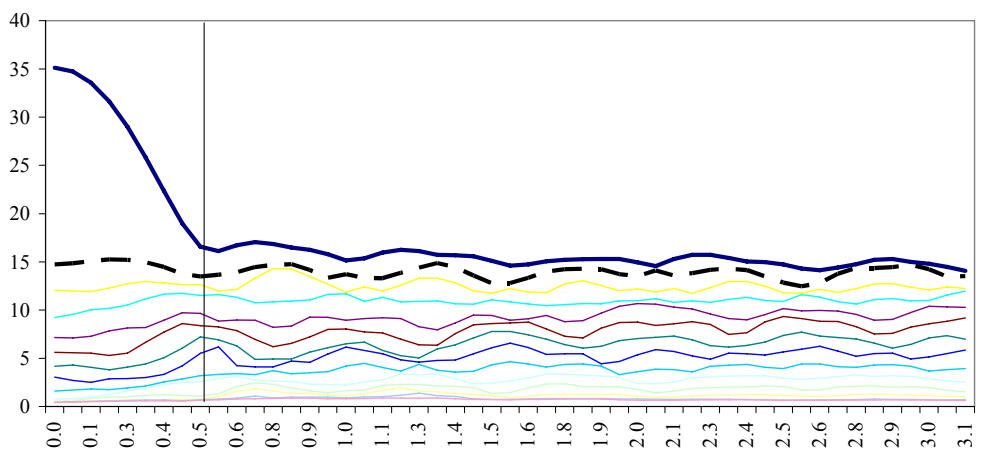
Sources: Eurostat; and Fund staff calculations. $1 /$ Corresponds to the first ten eigenvalues of the spectral density matrices. The top line represents the first common factor, the next from the top corresponds to the second common factor, etc.

suggesting that the seasonality in the original data had been successfully removed. The region between zero and the vertical line at 0.52 in the figures corresponds to periodicities exceeding one year. Therefore, it can be seen that the largest eigenvalue (corresponding to the first principal component) has greatest explanatory power in the medium to long run.

From Figure 2, it can be seen that two principal components explain 40 percent of the data variability at the policyrelevant frequency of $1 \frac{1}{2}$ years, rising to 50 percent in the long run. Moreover, the marginal contribution of the third principal component is considerably smaller than the second at these lower frequencies. Forty percent is chosen as threshold for identifying common shocks,
Figure 2. Cumulative Share of Data Variability Explained by the First Ten

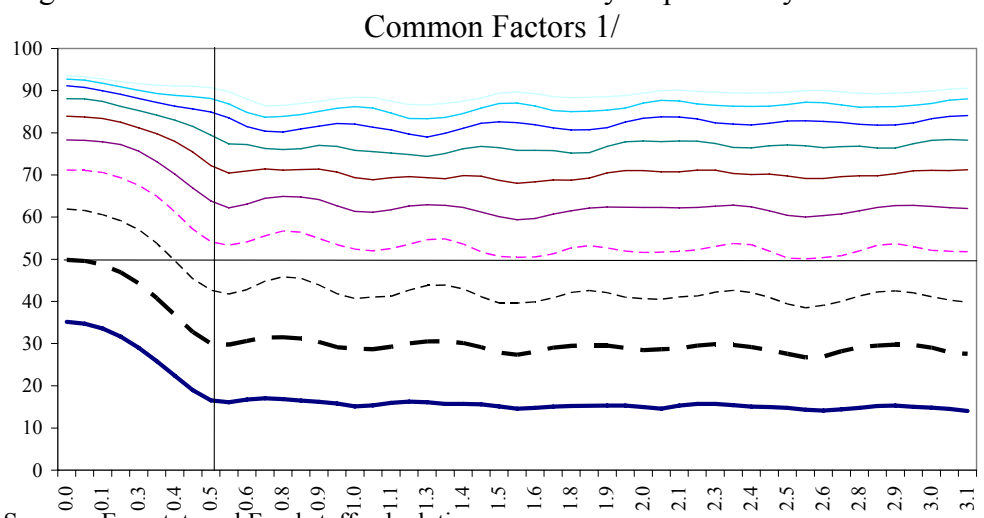
Sources: Eurostat; and Fund staff calculations.

$1 /$ Corresponds to the first ten eigenvalues of the spectral density matrices. The bottom line represents the first common factor, the next from the bottom corresponds to the second common factor, etc.

\footnotetext{
${ }^{16}$ The number of eigenvalues is equal to the number of data series. Only the ten largest eigenvalues are shown in the figures.
} 
somewhat lower than the 50 percent used by Cristadoro and others (2001), to avoid capturing an excessive amount of noise contained at the higher frequencies. ${ }^{17}$ Therefore, these first two principal components are chosen as the dynamic common factors for this data set. ${ }^{18}$ The remaining ( $N$ minus 2 ) principal components are interpreted as corresponding to the variance of the idiosyncratic components.

The next step in the GDFM involves selecting the number of static factors. This is done by applying Bai and Ng's (2002) panel algorithm, which minimizes the sum of squared errors from the regression of the data series on the static factors, subject to a penalty for the sample dimension. The value of this criterion is minimized at 16 static factors, which, together with the selection of two common shocks, implies that seven lags of the dynamic common factors are used in equation (1).

\section{B. Common-Origin Inflation in the 25 EU Countries}

Applying the GDFM to the set of price and nonprice variables decomposes them into their common and idiosyncratic components. Common-origin inflation in the 25 EU countries is then obtained by aggregating up the individual four-digit HICP common components using country- specific consumer basket weights. ${ }^{19}$ Figure 3 plots common-origin inflation and long-term common-origin inflation for each country, in addition to headline inflation, all in 12-month terms. The common-origin component of each country's inflation is that part of inflation attributable to shocks that are shared by all countries and sectors. The long-term common-origin inflation component is found by excluding common components at frequencies corresponding to periodicities of less than one year.

As anticipated by the PCA results, the common-origin component of inflation tracks quite closely broad movements in headline inflation in the time domain, while also achieving considerable smoothing by removing cross-section and cross-country noise. After filtering out high-frequency noise, the long-term common-origin component achieves an even greater degree of smoothing. The zero-mean restriction on the idiosyncratic components implies that common-origin and headline inflations cannot deviate systematically over time. As a result, the common-origin component in high-inflation countries will tend to exceed levels in lowinflation countries.

\footnotetext{
${ }^{17}$ As can be seen in Figure 1, the marginal contribution of the third and subsequent principal components is actually smaller at lower frequencies (i.e., in the longer run) than at higher frequencies.

${ }^{18}$ The resulting common-origin inflations are quite similar whether two or three common factors are used.

19 This differs from other authors, who include total HICP inflation in the GDFM-treating it as any other series - and therefore directly obtain a common-origin inflation component. However, this headline-based common-origin inflation measure could differ considerably from the measure based on disaggregated commonorigin inflation components. Prior to the aggregation, the common-origin component is multiplied by the standard deviation of the original series, and the series' mean is added back.
} 
Figure 3. EU25: Inflation Attributable to Two Common Factors

(Year-on-year, in percent)
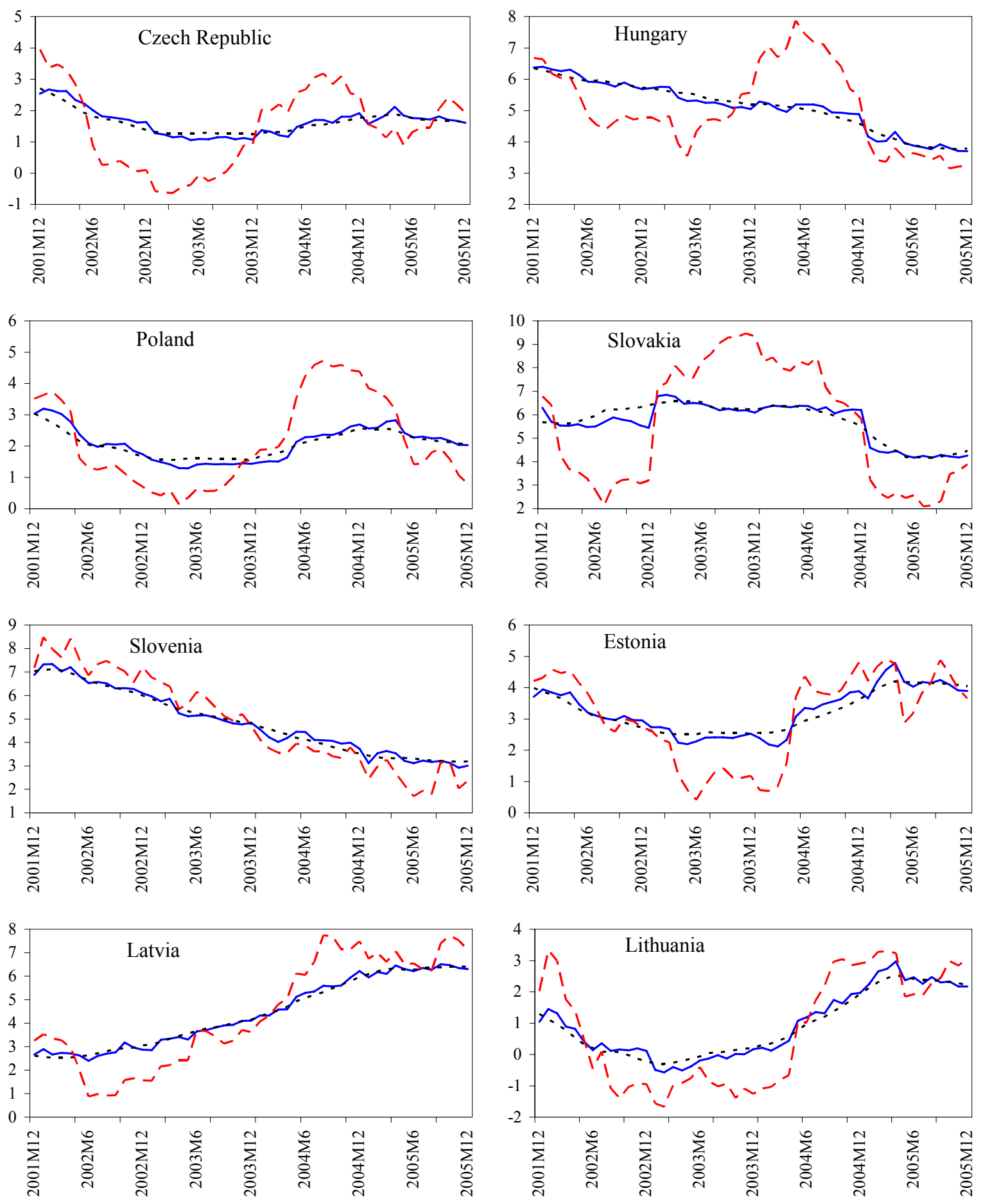
Figure 3 (Continued). EU25: Inflation Attributable to Two Common Factors

(Year-on-year, in percent)
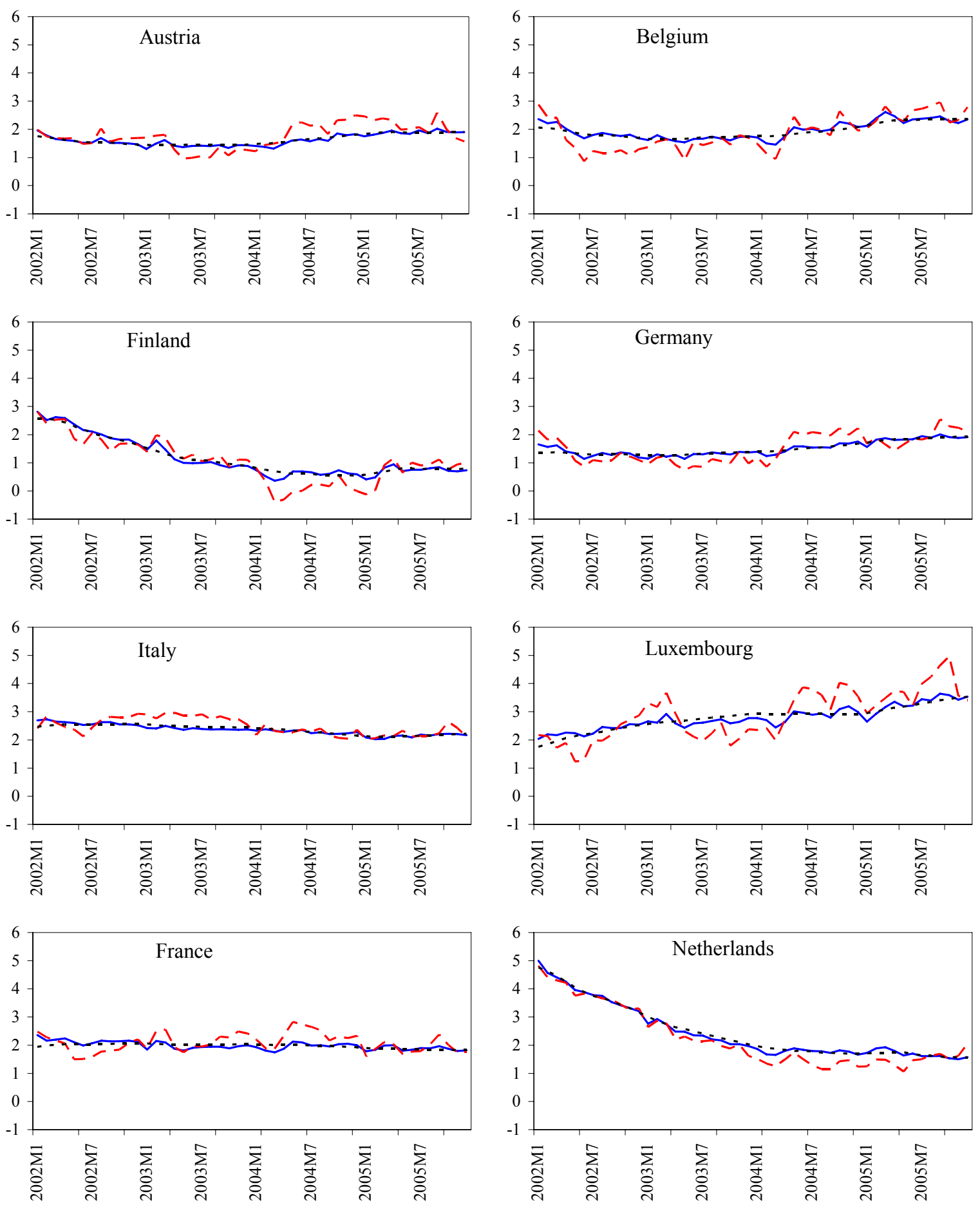
Figure 3 (Concluded). EU25: Inflation Attributable to Two Common Factors (Year-on-year, in percent)

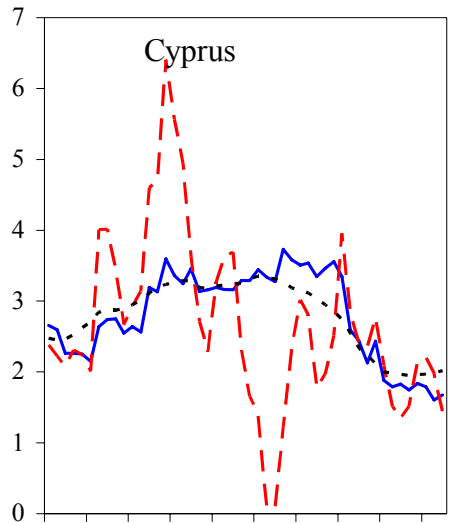

2002M1 2003M1 2004M1 2005M1

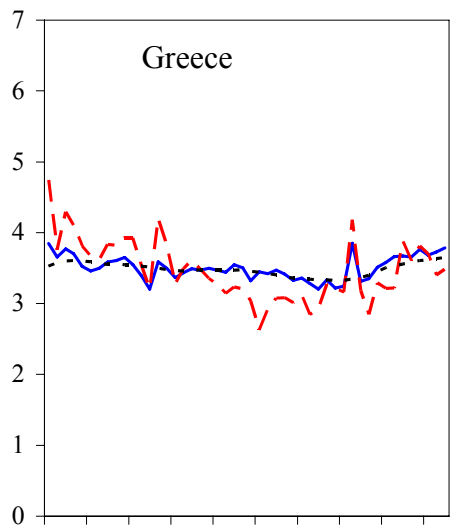

2002M1 2003M1 2004M1 2005M1

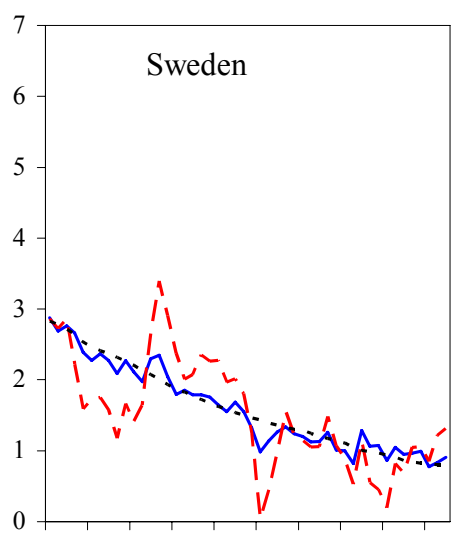

2002M1 2003M1 2004M1 2005M1

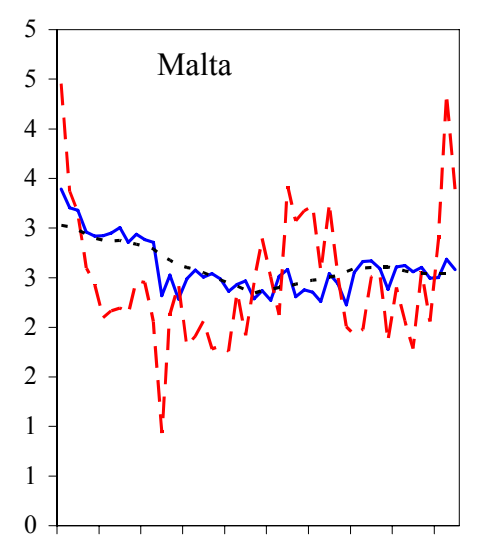

2002M1 2003M1 2004M1 2005M1

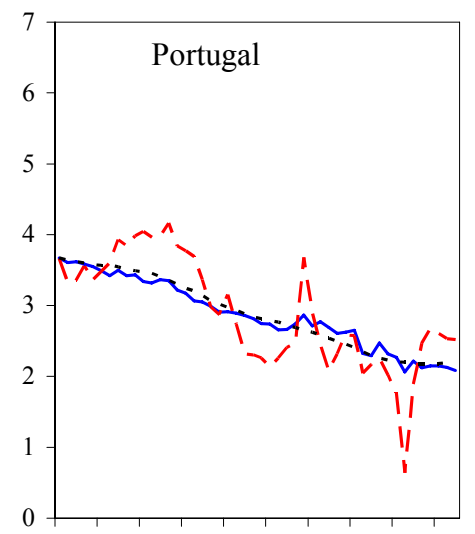

2002M1 2003M1 2004M1 2005M1

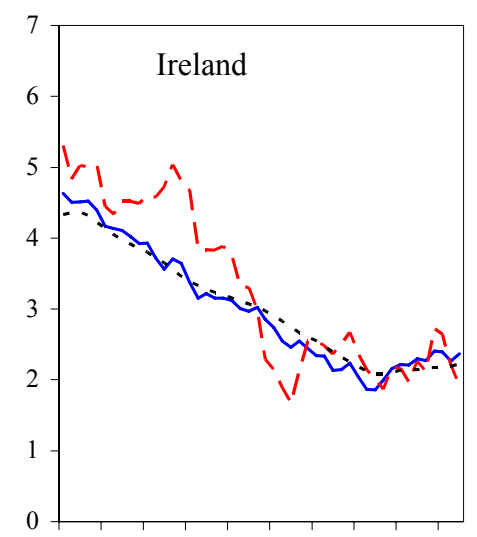

2002M1 2003M1 2004M1 2005M1
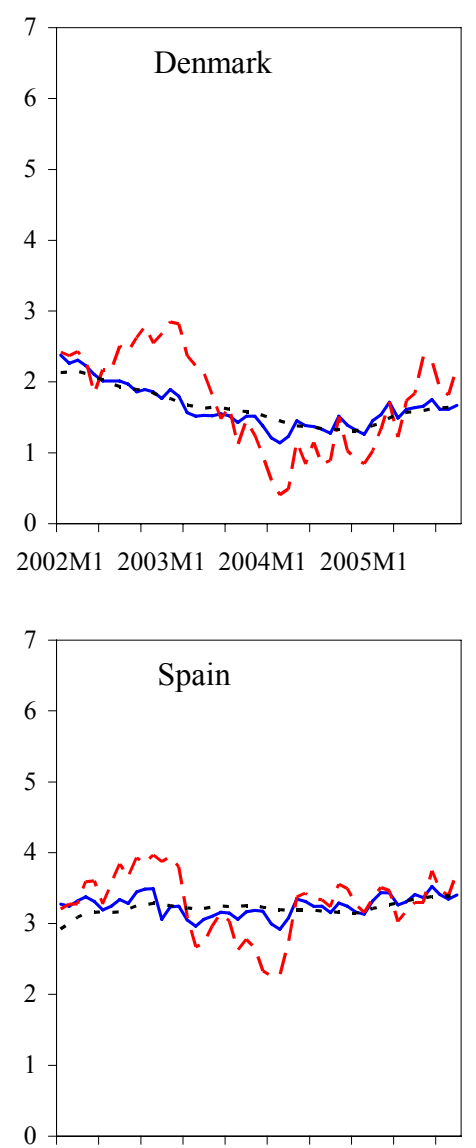

2002M1 2003M1 2004M1 2005M1

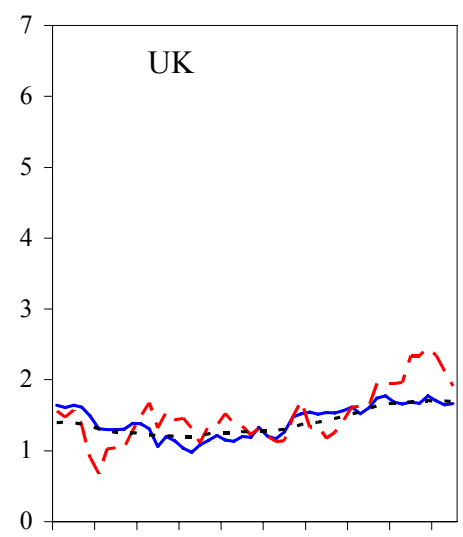

2002M1 2003M1 2004M1 2005M1

Source: IMF staff estimates.

------ Headline inflation

Common-origin inflation

- - - - - - Long-term common-origin inflation 
The proportion of total inflation variability accounted for by common shocks varies widely across the EU25, but averages to a little under 40 percent - consistent with the criterion used to choose the number of common factors. ${ }^{20}$ At the high end, common shocks account for more than 80 percent of the variability in the Netherlands' headline inflation; at the other extreme, little more than one-tenth of inflation variability is attributable to common shocks in the Czech and Slovak Republics. In terms of country groupings, the contribution of common factors to inflation variability is about equal (at around 35 percent) in the EU15 and the Baltics, but considerably lower in the five Central European countries (which is pulled down by Poland and the Czech and Slovak Republics). This suggests that the shocks that drive inflation in the EU15 are also important for inflation in the Baltics, Slovenia, and Hungary, while country-specific shocks are more prominent in Poland and the Czech and Slovak Republics.

Consistent with the law of one price, the impact of common shocks is found to be stronger in more open economies, suggesting that trade is an important conduit in propagating price movements. This is especially true for inflation of tradable goods prices (Figure 4). Moreover, for the most open economies, the impact of common shocks is somewhat stronger than for less open economies: the trend line for the most open economies in Figure 4 is steeper than the trend line for less open economies. Nonetheless, it is likely that potential (as distinct from actual) cross-border trade in the context of contestable markets

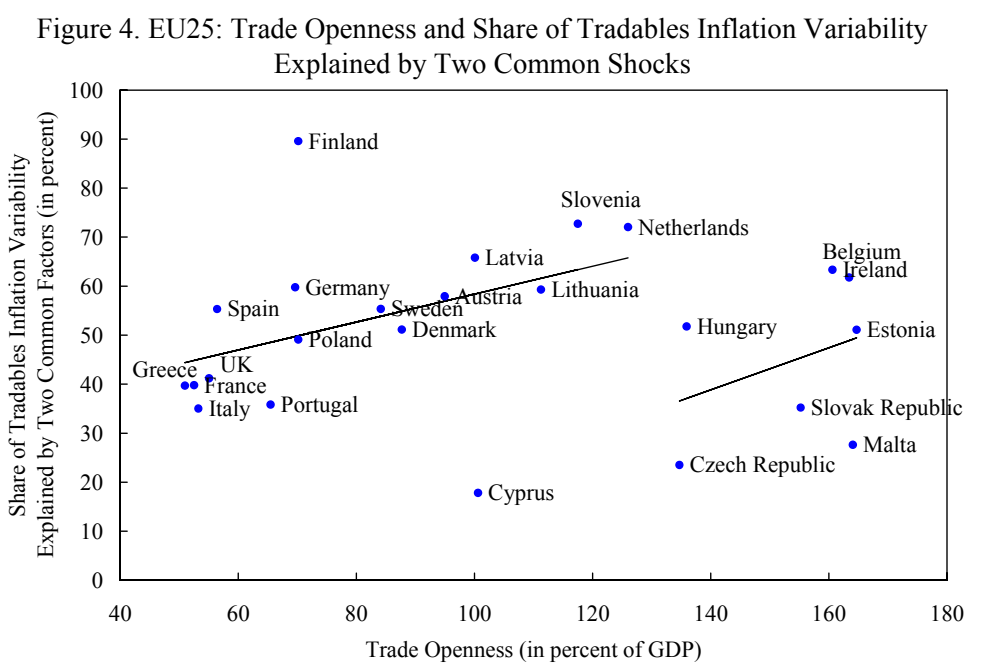
may also be effective in propagating price shocks between countries.

\section{Explaining Intra-EU Common-Origin Inflation Differentials}

Cross-country variation in common-origin inflations can be attributed to differences in economic fundamentals, institutions, and policies. In this framework, such effects can manifest in two ways: (i) the loading factors for individual inflation componentsrepresented by the $b_{j h k}$ 's in equation (1) - may exhibit cross-country heterogeneity; and (ii) the HICP weights used to aggregate up individual inflation series into headline inflation may vary across countries, reflecting differences in relative prices and incomes, and (perhaps also) preferences. It is these phenomena that explain why common-origin inflation during 2001-05

\footnotetext{
${ }^{20}$ Nonetheless, the variability of headline inflation is significantly higher in the EU8 than in the EU15.
} 
averaged $2 \frac{1}{4}$ percent in the EU15, against 3 percent in the Baltics and 4 percent in the CEE5 (Table 2). Within a closely integrated economic region, competition and arbitrage opportunities should eventually eliminate much of the disparity, causing common-origin inflations to gradually converge. However, this is likely to be a very lengthy process and intertwined more generally with income convergence.

Table 2. EU25: Average Year-on-Year Inflation, 2001-2005

\begin{tabular}{|c|c|c|c|}
\hline & $\begin{array}{c}\text { Common- } \\
\text { origin } \\
\text { inflation }\end{array}$ & $\begin{array}{c}\text { Long-term } \\
\text { common-origin } \\
\text { inflation }\end{array}$ & $\begin{array}{l}\text { Headline } \\
\text { inflation }\end{array}$ \\
\hline Czech Republic & 1.6 & 1.6 & 1.4 \\
\hline Hungary & 5.1 & 5.1 & 5.1 \\
\hline Poland & 2.1 & 2.1 & 2.1 \\
\hline Slovak Republic & 5.7 & 5.7 & 5.6 \\
\hline Slovenia & 4.9 & 4.8 & 4.9 \\
\hline Estonia & 3.3 & 3.2 & 3.1 \\
\hline Latvia & 4.4 & 4.4 & 4.5 \\
\hline Lithuania & 1.0 & 0.9 & 0.8 \\
\hline Baltic average & 2.9 & 2.9 & 2.8 \\
\hline CEE5 average & 3.9 & 3.9 & 3.8 \\
\hline EU8 average & 3.5 & 3.5 & 3.4 \\
\hline Austria & 1.6 & 1.6 & 1.8 \\
\hline Belgium & 2.0 & 1.9 & 1.9 \\
\hline Cyprus & 2.8 & 2.8 & 2.7 \\
\hline Denmark & 1.7 & 1.7 & 1.7 \\
\hline Finland & 1.2 & 1.2 & 1.1 \\
\hline France & 2.0 & 2.0 & 2.1 \\
\hline Germany & 1.5 & 1.5 & 1.5 \\
\hline Greece & 3.5 & 3.5 & 3.5 \\
\hline Ireland & 3.0 & 3.0 & 3.3 \\
\hline Italy & 2.4 & 2.4 & 2.5 \\
\hline Luxembourg & 2.8 & 2.8 & 2.9 \\
\hline Malta & 2.6 & 2.6 & 2.5 \\
\hline Netherlands & 2.5 & 2.5 & 2.3 \\
\hline Portugal & 2.9 & 2.9 & 2.9 \\
\hline Spain & 3.2 & 3.2 & 3.3 \\
\hline Sweden & 1.6 & 1.6 & 1.6 \\
\hline UK & 2.7 & 2.7 & 2.7 \\
\hline EU15 average & 2.3 & 2.3 & 2.3 \\
\hline
\end{tabular}

To explore the determinants of cross-country differences in the levels of the common components of inflation, a series of estimations is performed using data for pre-2007 EU countries. ${ }^{21}$ Given the focus on structural and institutional indicators, which - by their

\footnotetext{
${ }^{21}$ Missing indicators of institutional quality for Cyprus, Luxembourg, and Malta restrict the sample to 22 countries.
} 
nature - are slow to vary, or measured only infrequently, cross-section estimations are performed. Accordingly, common-origin inflation is used as the dependent variable. ${ }^{22}$ The limited number of observations therefore dictates parsimonious equation specifications. Since the main objective is to explain inflation variation within the EU, all variables are defined relative to an EU-average benchmark. This approach also has the advantage of abstracting from factors (including globalization and technological progress) that affect inflation levels more or less equally in all countries. ${ }^{23}$

Three categories of regressors are considered: macroeconomic, institutional, and political variables. To capture the effect of relative economic development, the initial level of relative prices is included, measured as of $2001 .^{24}$ This variable measures the gap between an individual country's price level and the EU average, and, hence, the price adjustments required to achieve a uniform EU-wide pricing structure. In addition, the relative price level also proxies the "distance" to convergence in real incomes. ${ }^{25}$

The set of macroeconomic variables tested in the model includes the change in the nominal effective exchange rate, size of government, and trade openness. Also tested is a range of institutional indicators, including unionization coverage, quality of the legal system, restrictiveness of labor and product market regulations, and political stability. Appendix II provides a detailed description of the data.

The empirical results for the cross-country regressions are shown in Table 3 . The first column contains the results for the estimations including only the development and macroeconomic regressors. Column II includes development, macroeconomic, and institutional regressors, while columns III-VII also include interactions between individual institutional indicators. The discussion below is based on the regression in column VII, which is regarded as the baseline since it is both parsimonious and highlights the main conclusions.

\footnotetext{
${ }^{22}$ The empirical results are not sensitive to the choice of common-origin, or long-term common-origin, inflation as the dependent variable.

${ }^{23}$ See Borio and Filardo (2006).

${ }^{24}$ The relative price level is defined as the ratio of the purchasing power parity (PPP) and market exchange rates for each country. The PPP exchange rate measures how many goods the domestic currency buys within the home country relative to the numeraire country (the EU average in this analysis), while the market exchange rate measures how much of the numeraire currency can be bought with the domestic currency in the foreign exchange market. The ratio of the two exchange rates therefore indicates the cost of goods at home relative to the numeraire country.

${ }^{25}$ An implication of the Balassa-Samuelson theory is that a country with a relatively low ratio of tradables to nontradables productivity will have a depreciated real exchange rate, i.e., a relatively low domestic price level (de Broeck and Sløk, 2001). Given the very high correlation between initial relative prices and PPP-based per capita GDP, the latter variable is not included in the analysis.
} 
Table 3. Regressions of Average Year-on-Year Common-Origin Inflation on Macroeconomic, Institutional, and Political Variables, 2002-05

\begin{tabular}{|c|c|c|c|c|c|c|c|}
\hline & $\mathrm{I}$ & II & III & IV & $\mathrm{V}$ & VI & VII \\
\hline \multirow[t]{2}{*}{ Constant } & 0.000 & 0.004 & 0.014 & 0.016 & 0.018 & 0.016 & 0.015 \\
\hline & {$[0.04]$} & {$[0.52]$} & {$[1.76]$} & {$[1.86]$} & {$[1.60]$} & {$[1.05]$} & {$[2.07]$} \\
\hline \multirow[t]{2}{*}{ Relative price level in 2001} & -0.023 & -0.023 & -0.038 & -0.033 & -0.034 & -0.033 & -0.032 \\
\hline & {$[4.48]^{* *}$} & {$[2.54]^{*}$} & {$[4.15]^{* *}$} & {$[3.48]^{* *}$} & {$[3.27]^{* *}$} & {$[3.35]^{* *}$} & {$[3.70]^{* *}$} \\
\hline \multirow[t]{2}{*}{ Nominal effective appreciation } & -0.322 & -0.356 & -0.390 & -0.352 & -0.353 & -0.353 & -0.353 \\
\hline & {$[3.60]^{* *}$} & {$[3.71]^{* *}$} & {$[4.83]^{* *}$} & {$[4.08]^{* *}$} & {$[3.96]^{* *}$} & {$[3.73]^{* *}$} & {$[4.24]^{* *}$} \\
\hline \multirow[t]{2}{*}{ Labor market flexibility } & & -0.004 & -0.020 & -0.020 & -0.023 & -0.020 & -0.020 \\
\hline & & {$[1.28]$} & {$[2.88]^{*}$} & {$[2.57]^{*}$} & {$[1.94]$} & {$[2.44]^{*}$} & {$[2.67]^{*}$} \\
\hline \multirow[t]{2}{*}{ Legal quality } & & -0.007 & -0.001 & -0.012 & -0.012 & -0.012 & -0.012 \\
\hline & & {$[0.84]$} & {$[0.09]$} & {$[1.48]$} & {$[1.47]$} & {$[0.85]$} & {$[1.54]$} \\
\hline \multirow[t]{2}{*}{ Product market flexibility } & & 0.009 & -0.008 & & & & \\
\hline & & {$[1.52]$} & {$[0.72]$} & & & & \\
\hline \multirow[t]{2}{*}{ Political instability (CNTS) } & & -0.001 & -0.002 & 0.000 & -0.002 & 0.000 & \\
\hline & & {$[0.34]$} & {$[0.72]$} & {$[0.06]$} & {$[0.30]$} & {$[0.01]$} & \\
\hline \multirow[t]{2}{*}{ Labor market flexibility * legal quality } & & & -0.002 & 0.014 & 0.015 & 0.014 & 0.014 \\
\hline & & & {$[0.19]$} & {$[2.31]^{*}$} & {$[2.14]$} & {$[2.16]^{*}$} & {$[2.39]^{*}$} \\
\hline \multirow[t]{2}{*}{ Labor market flexibility * product market flexibility } & & & 0.018 & & & & \\
\hline & & & {$[1.64]$} & & & & \\
\hline \multirow[t]{2}{*}{ Political instability $(\mathrm{CNTS}) *$ labor market flexibility } & & & & & 0.002 & & \\
\hline & & & & & {$[0.31]$} & & \\
\hline \multirow[t]{2}{*}{ Political instability (CNTS) * legal quality } & & & & & & 0.000 & \\
\hline & & & & & & {$[0.01]$} & \\
\hline Observations & 22 & 22 & 22 & 22 & 22 & 22 & 22 \\
\hline R-squared & 0.57 & 0.66 & 0.80 & 0.71 & 0.71 & 0.71 & 0.71 \\
\hline
\end{tabular}

Consistent with price convergence, the initial relative price level is found to be significantly negatively correlated with differences in common-origin inflation across the $\mathrm{EU}, \mathrm{a}$ result that is robust across model specifications. Moreover, the initial relative price level enters as a $\log$ function, as shown in Figure 5, implying that (i) countries with initial prices below (above) the EU average will experience higher(lower)-than-average inflation rates; and (ii) initial relative prices affect subsequent inflation in a nonlinear manner, with negative price gaps having a proportionately larger effect on inflation Figure 5. Contribution of Price Gaps to Common-Origin Inflation Differentials (In percentage points) differentials than positive price gaps.

Nominal effective exchange rate changes are also found to be an important determinant of intra-EU common-origin inflation differentials. The negative coefficient implies that a country experiencing a more rapid nominal effective depreciation than the EU average will, ceteris paribus, see inflation in excess of the group average. As a consequence, countries running flexible exchange rate regimes against the euro are likely to experience larger absolute deviations from EU-average inflation than euro members or countries whose currencies are pegged to the euro. Several other explanatory variables found to affect 
inflation in other studies — including trade openness and size of government — were not significant factors in explaining intra-EU common-origin inflation variation. ${ }^{26}$

The foregoing empirical results are illustrated in Figure 6, which shows the contribution of initial relative prices and nominal effective exchange rate changes to common-origin inflation differentials. For most of the EU8, the initial relative price level is an important factor in explaining inflation differentials relative to the EU average. The exception is Slovenia, where the initial relative price level (and per capita income) was substantially above that of the other EU8 and close to the EU average. In the Slovak Republic, which had the lowest price level in 2001, this factor added more than $2 \frac{1}{4}$ percentage points to the inflation differential. Low initial prices contributed

Figure 6. EU25: Contribution of Relative Price Convergence and Nominal Effective Appreciation to Common-Origin Inflation (In percentage points)

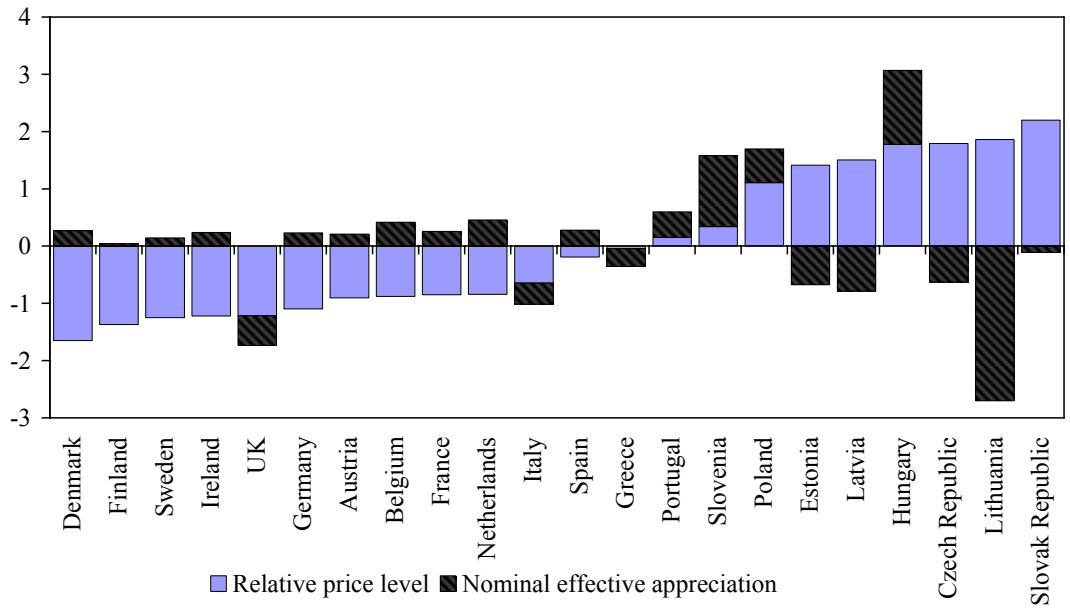
around 1-2 percentage points to common-origin inflation differentials in Lithuania, Latvia, the Czech Republic, Hungary, Estonia, and Poland. At the other end of the spectrum, higherthan-average price levels were associated with negative inflation differentials in Denmark, Finland, Ireland, Sweden and the U.K., although the absolute magnitudes are smaller than for the below-average price level countries. Nominal effective appreciations resulted in the largest (negative) contribution to common-origin inflation differentials in Lithuania, reflecting the strengthening of the U.S. dollar against the euro at the time the litas was pegged to the US dollar. Nominal effective depreciations added more than 11/4 percentage points to common-origin inflation differentials in Hungary and Slovenia.

Several institutional variables are also found to significantly influence long-term commonorigin inflation in the EU, supporting the notion that a culture of stability and economic flexibility are important for maintaining low inflation. As can be seen in equations III-VII, more flexible labor market institutions relative to the EU average (a higher value of the index indicates greater flexibility) are associated with smaller inflation differentials. Legal system quality (a higher value indicates better rule of law) is only significant on its own at the 15 percent level; however, its effect is significant (and positive) when interacted with labor

\footnotetext{
${ }^{26}$ While trade openness is associated with a larger contribution of common to headline inflation variance, it is not found to significantly affect the level of common-origin inflation. This finding is consistent with the notion that contestable markets and trade potential exert a greater influence than realized trade on pricing behavior.
} 
market flexibility. This result implies that an efficient and independent legal system can mitigate the adverse inflationary impact of labor market rigidities.

These results are presented graphically in Figure 7, which shows the contribution of labor market flexibility and legal system quality to commonorigin inflation differentials. Rigid labor markets are found to have raised inflation differentials by 1 percentage point or more in Slovenia, Portugal, Greece, Spain, and France, while very flexible labor markets in the Czech Republic, and to a somewhat lesser extent, the U.K., Belgium and Denmark, narrowed their inflation differentials by $3 / 4$ to almost $1 \frac{1}{2}$ percentage points.

Figure 7. EU25: Contribution of Labor Market Flexibility and Legal Quality to Common-Origin Inflation (In percentage points)

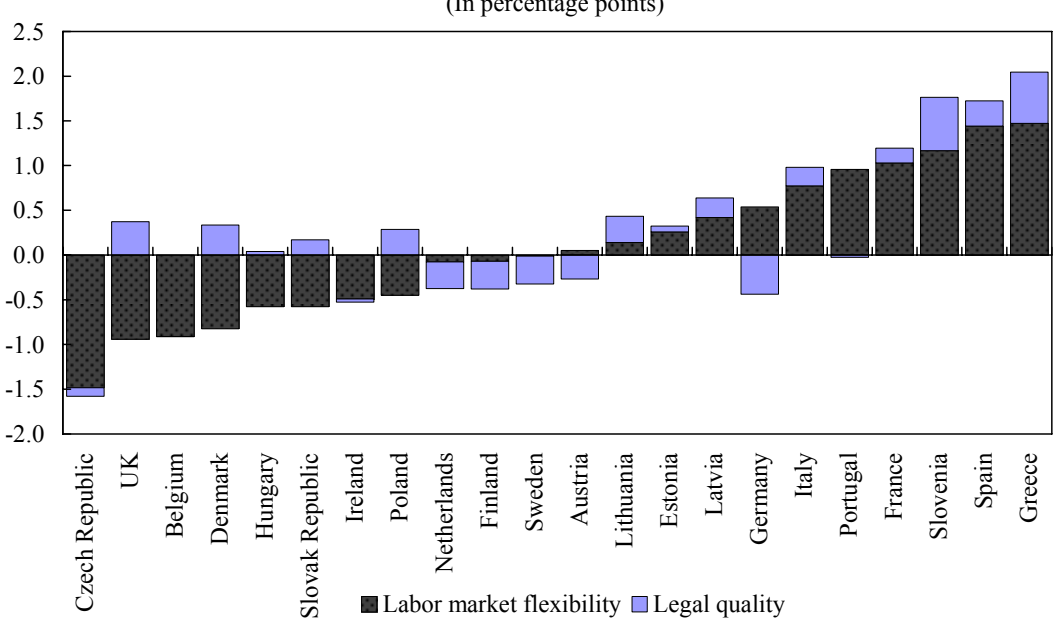

In the Baltics, labor market flexibility is slightly below average (reflecting primarily the severity of restrictions on firing workers), thereby adding marginally to inflation. Even in these countries, however, the effect on inflation differentials is modest and small in scale in comparison to the effect of relative price gaps. Several countries with rigid labor market regulations also possess relatively weak legal systems, thereby accentuating the proinflation effect of labor market rigidities. As a result, easing labor market restrictions and improving legal quality to EU best practice (the U.K. for the former and Finland for the latter) could substantially dampen common-origin Figure 8. EU25: Effect on Common-Origin Inflation of Improving Legal System and Labor Market Flexibility (In percentage points)

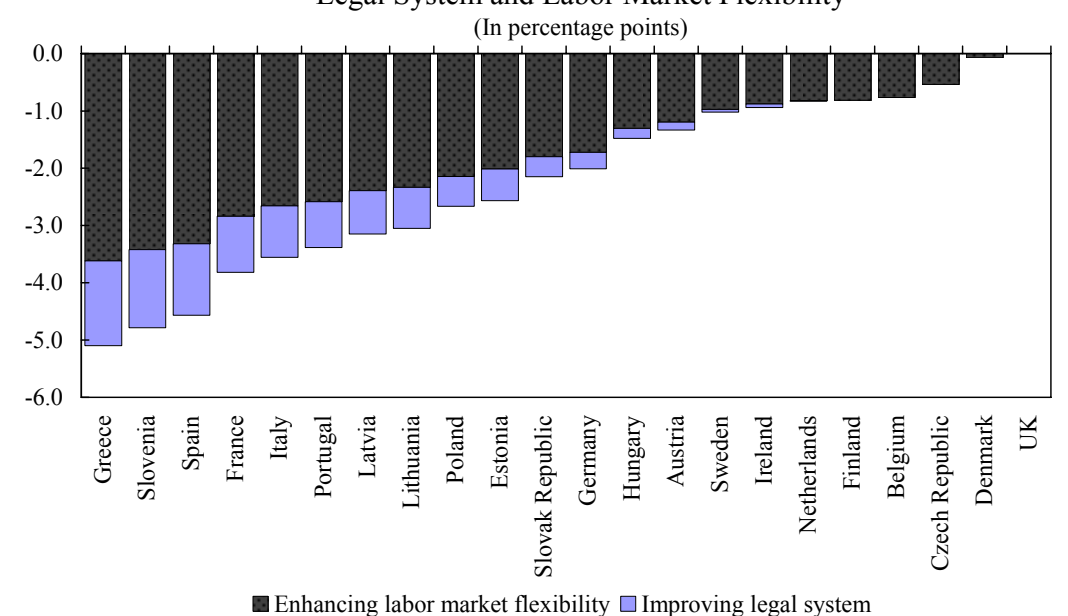
inflation, including in a number of prospective euro members (Figure 8). 
Several institutional variables, including political stability and central bank independence, that are shown to be important determinants of inflation in other studies are either not relevant or not statistically significant in the EU sample. In part, this reflects the limited variability of these indicators within the EU. As regards political stability, the EU25 countries are clustered near the top of the distribution of countries on the Kaufmann and Kray (2006) index (implying high stability), whereas global variation is substantially larger (Figure 9). Moreover, variability of central bank independence within the EU is nonexistent because - on

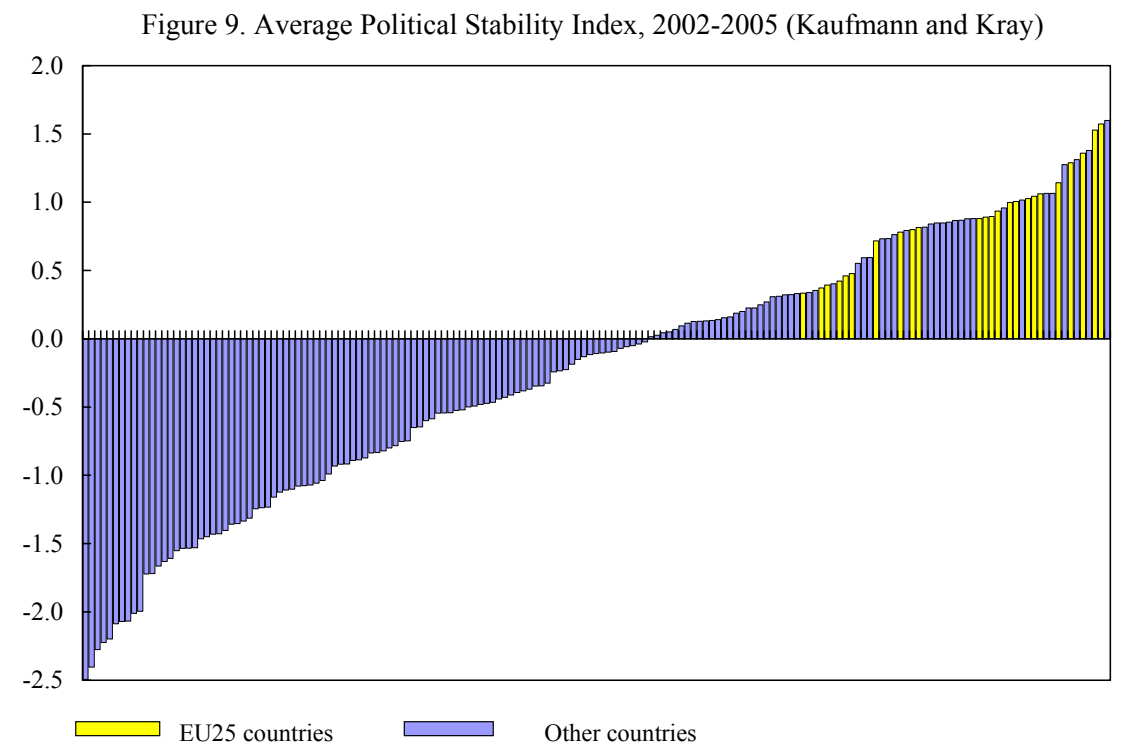
the one hand - independence is a prerequisite for EU membership, and — on the other - the majority of the EU25 share a common central bank. Trade union density and flexibility of product market regulations (where considerable cross-country variation do exist) were not found to significantly influence common-origin inflation differentials. ${ }^{27}$

The results underline the strong inertia in common-origin inflation differentials within the EU, providing an explanation for the inflation persistence observed within the EU15 and euro area countries. ${ }^{28}$ This conclusion derives from the fact that most of the regressors that are found to be important determinants of inflation differentials are of a structural or institutional nature and, therefore, evolve only slowly or may not be amenable to substantive change through policy reforms alone. Indeed, relative price levels changed in absolute terms only by a cumulative 3 percentage points on average during 2002-05, although changes were somewhat larger in a number of EU8 countries. As regards institutions, policies can affect de jure characteristics in the short run, but the payoff in terms of improved economic flexibility and greater legal certainty will depend on implementation and can, therefore, take considerable time to materialize.

\footnotetext{
${ }^{27}$ The effect of unionization on inflation is likely to be already captured by the indicator of labor market restrictivenenss.

${ }^{28}$ See ECB 2003 for an overview, as well as Altissimo, Benigno, and Palenzuela (2005) and Angeloni and Ehrmann (2004).
} 
The results also show that sizable gaps between price levels in most EU8 countries relative to their more advanced EU counterparts raise their common-origin inflation rates above the average for the rest of the group. Moreover, for Lithuania (and, to a lesser extent, Latvia), where a relatively large nominal effective appreciation helped to subdue common-origin inflation, the shift to a euro peg likely raised inflation somewhat. However, for Sloveniawhich, historically, saw a faster nominal effective depreciation relative to other EU members - inflation differentials can be expected to narrow in response to the adoption of a fixed euro parity and EMU entry.

The results also suggest that several of the EU8 countries could face considerable challenges in bringing down inflation to meet the Maastricht criterion within the next few years. ${ }^{29}$ This is because relative underdevelopment, as captured by a negative price level gap, implies, ceteris paribus, higher common-origin inflation in non-euro EU8 countries than among the rest of the EU. Moreover, institutional factors found to influence common-origin inflation generally change only gradually and, in the near term, may be little affected by policy decisions. As a result, the EU8 may need to rely on sizable negative idiosyncratic inflation shocks to reduce headline inflation to Maastricht levels.

\section{Idiosyncratic Inflation and the Maastricht Criterion}

Idiosyncratic shocks have, on occasion, caused sizable deviations - both positive and negative - between headline and common-origin inflation. During 2001-05, country-specific inflations lay within $+/-3.5$ percent for the 25 countries; for the EU15, however, the range was narrower $[-3.1,+2.8$ percent], although in some instances the shocks were still sizable relative to headline inflation (Figure 10). Among the EU8, idiosyncratic inflations appear to have tracked quite closely the inflation contributions of changes in regulated prices and indirect taxes (Figure 11), suggesting that policy-induced price changes are an important source of own price shocks in these countries. Country-specific business cycles are also likely to be reflected in idiosyncratic inflation.

The incidence of - at times, sizable - idiosyncratic inflations could affect the outcome of Maastricht inflation test. That idiosyncratic factors could significantly skew the distribution of inflation and lower the criterion has been recognized by others, including the EC (2000), and motivated the decision by the ECB and EC to exclude Lithuania—which was then undergoing a modest deflation owing to the liberalization of its telecommunications sectorfrom the calculation of the inflation reference rate in 2004. Our GDFM framework allows us to identify whether idiosyncratic factors affect the level of the inflation criterion and, if so, quantify their magnitude.

\footnotetext{
${ }^{29}$ It is also worth recalling that, while the common-origin inflation differentials estimated here are defined relative to the EU average, the Maastricht inflation reference rate is calculated on the basis of average headline inflation in the three lowest (nonnegative) inflation countries.
} 
Figure 10. EU25: Idiosyncratic Inflation

(Year-on-year, in percent)
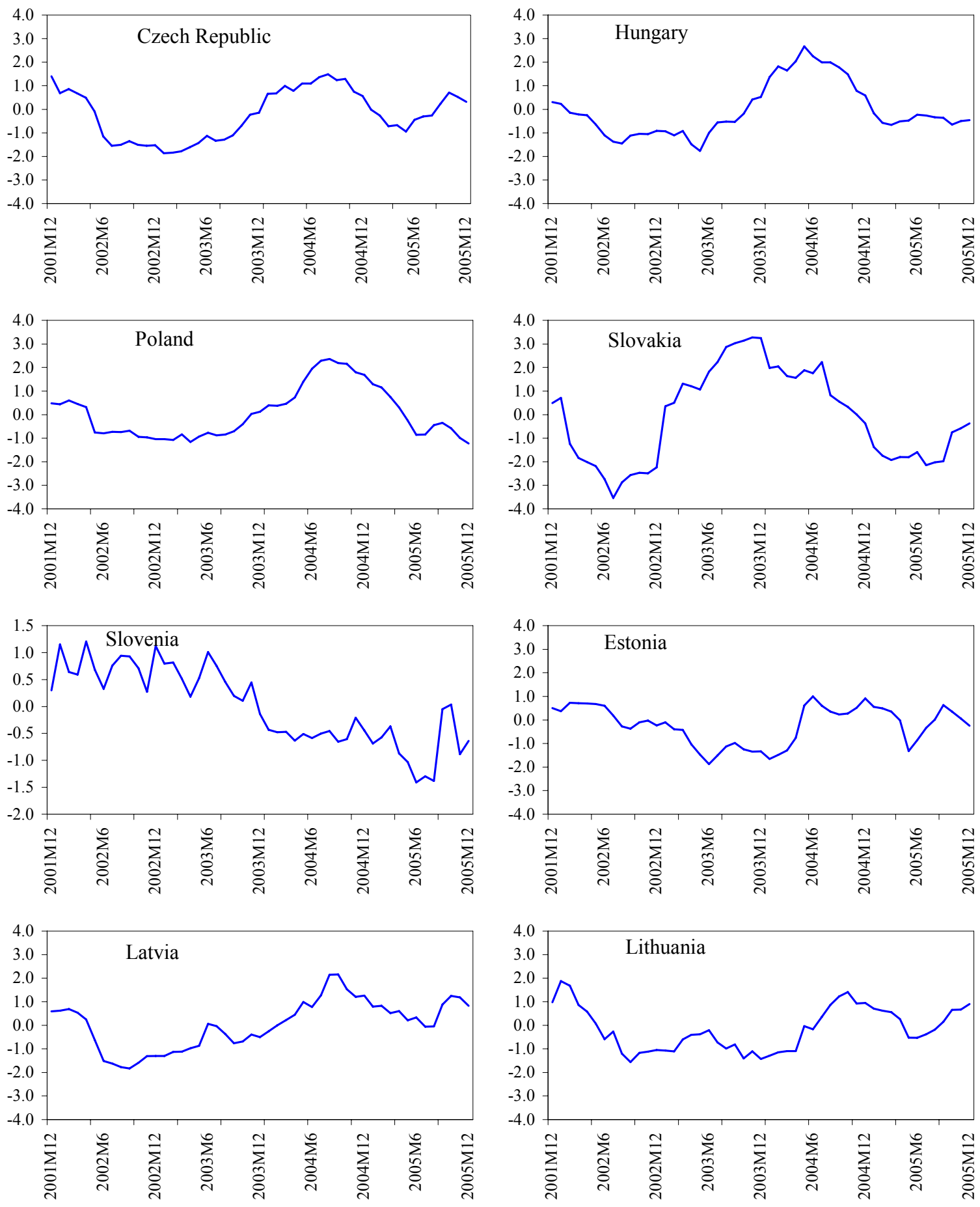
Figure 10 (Continued). EU25: Idiosyncratic Inflation (Year-on-year, in percent)
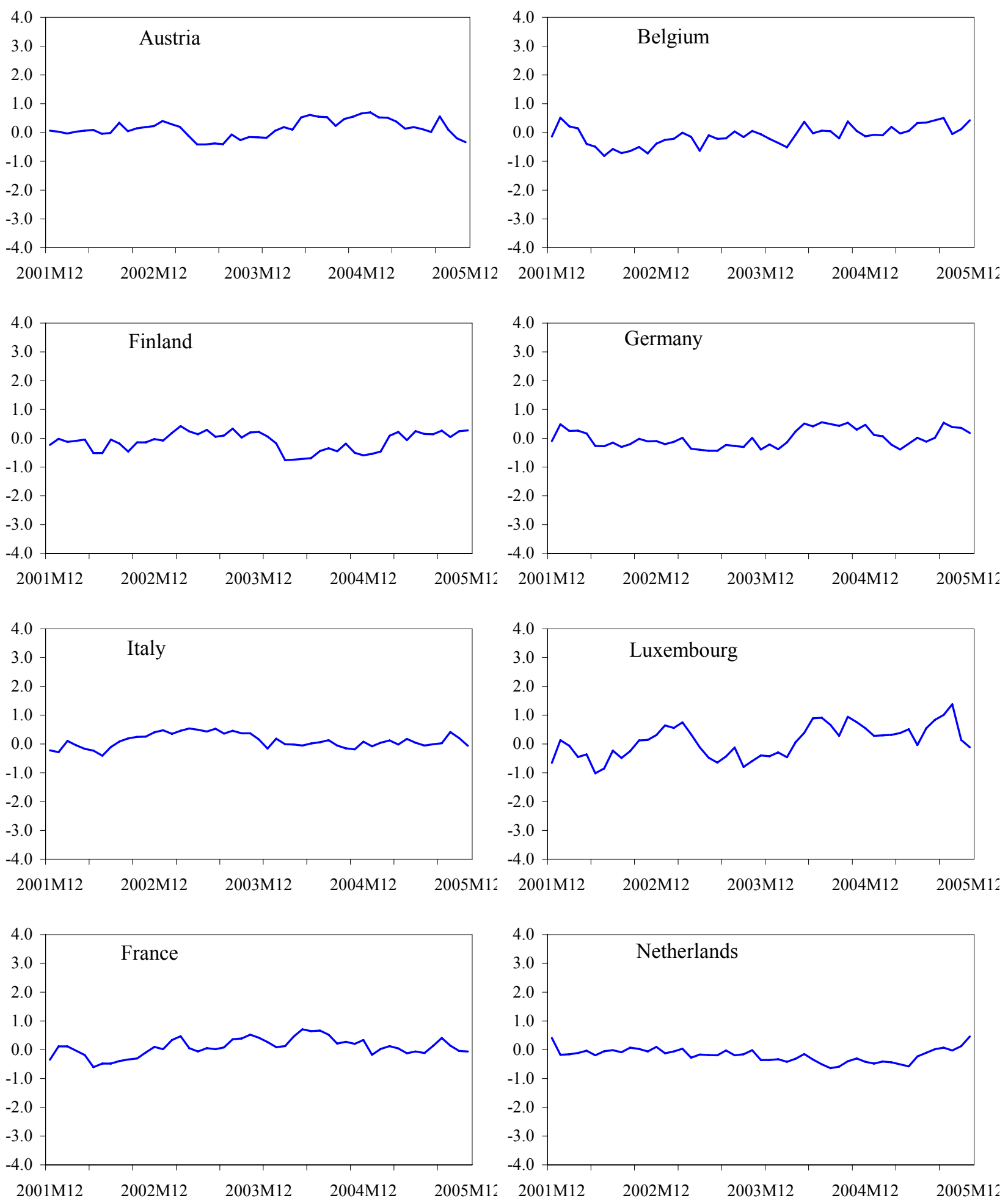
Figure 10 (Concluded). EU25: Idiosyncratic Inflation

(Year-on-year, in percent)
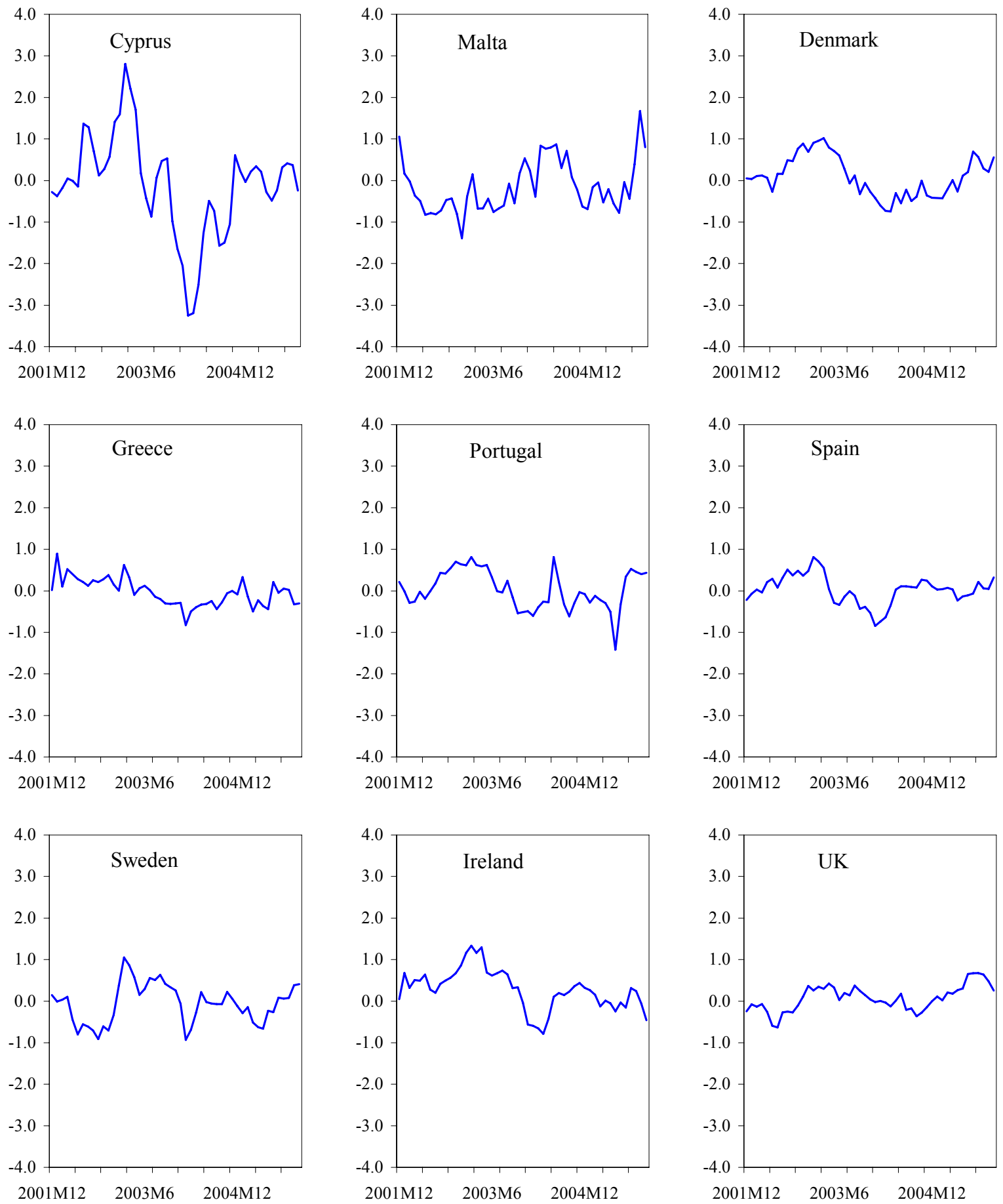

Source: Fund staff estimations. 
Figure 11. EU8: Idiosyncratic Inflation and Changes in Indirect Taxes and Regulated Prices
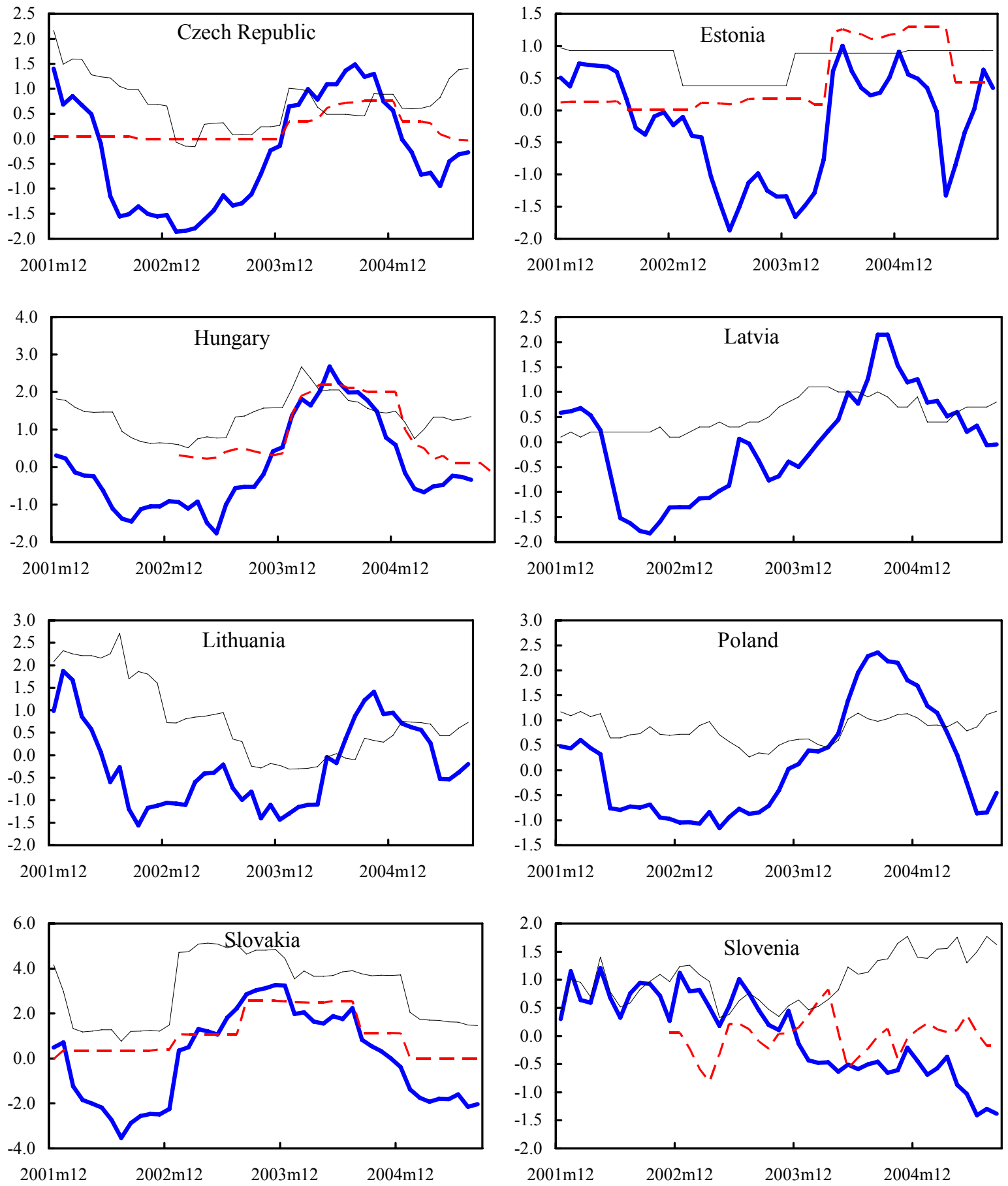

Sources: Country authorities and Fund staff calculations.

Idiosyncratic inflation

- - Influence of indirect taxes changes (contribution to total, in percent)

Regulated prices (contribution to total, in percent) 
Meeting the inflation criterion will be more difficult in the presence of either positive own idiosyncratic shocks or negative idiosyncratic shocks affecting other countries. Regarding the latter, the criterion would be lowered if low common-origin inflation countries were subjected to negative country-specific shocks. Moreover, the criterion may be systematically pulled down if countries chosen to set the criterion on the basis of their low headline inflation rates achieve low inflation through the occurrence of negative idiosyncratic shocks.

Using the common-origin and idiosyncratic inflation rates generated by the GDFM, idiosyncratic shocks are shown to have lowered the level of the Maastricht criterion in two ways. First, the three EU countries with the lowest (nonnegative) headline inflation in each period had, on average, common-origin inflation rates (dashed line in Figure 12) that systematically exceeded the average of their headline inflations (thick line). This difference reflects the incidence of negative idiosyncratic shocks in low-headline-inflation countries. More recently, this difference has been on the order of 0.2 percentage point, but has reached $1 / 2$ percentage point at times during 2003-05. Second, negative idiosyncratic shocks

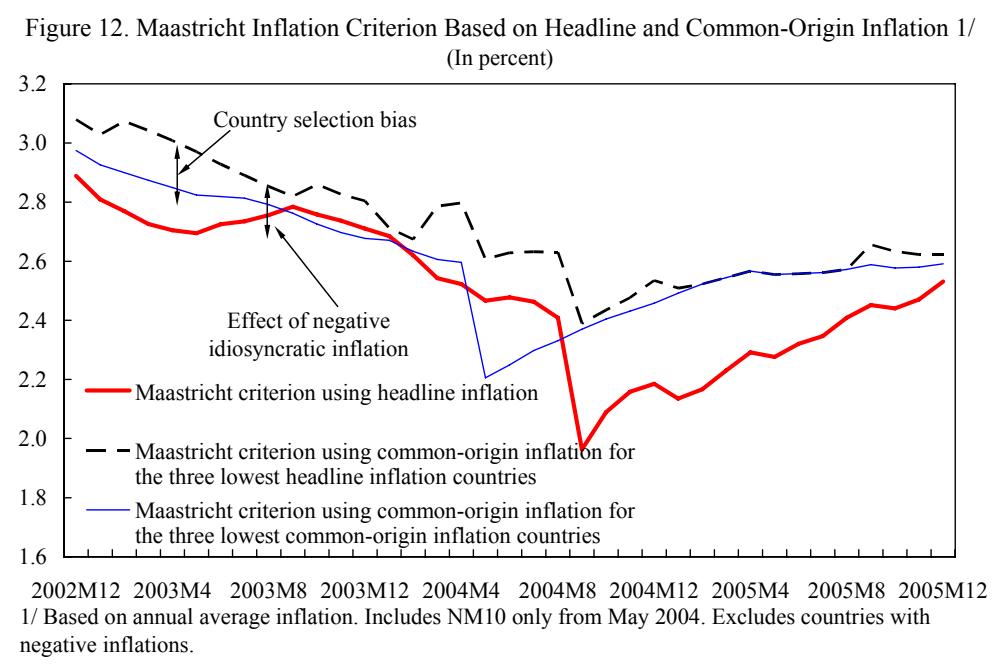
have influenced the selection of countries chosen to set the inflation criterion. To detect this country selection bias, a common-origin criterion is calculated based on common-origin inflation in the three countries with the lowest common-origin (rather than headline) inflation (thin line). Typically - although not always - the value of the common-origin criterion (thin line) is below the average common-origin inflations of the three countries with the lowest headline inflation (dashed line), indicating that the sets of countries used to define the common-origin criterion and the headline criterion differ. Therefore, during such periods when the groups of countries differed, countries selected to set the criterion on the basis of their low headline inflation did not correspond to the countries with the lowest commonorigin inflation. ${ }^{30}$ Together, these results reveal that negative idiosyncratic shocks have typically influenced the selection of countries that establish the Maastricht inflation criterion and-given the countries selected-dampened the level of the criterion.

\footnotetext{
${ }^{30}$ Mid-2004 corresponded to a period in which low common-inflation countries experienced relatively large positive idiosyncratic shocks (which disqualified them as low-headline-inflation countries), while countries with higher common-origin inflation exerienced large negative idiosyncratic shocks.
} 
Looking back to the late 1990s, when the EU15 countries were aiming to qualify for euro entry, idiosyncratic shocks are found to have facilitated one country's compliance with the Maastricht inflation hurdle. ${ }^{31}$

Rather than through lowering the criterion (as discussed above), this compliance came about through the incidence of negative own shocks. ${ }^{32}$

Figure 13 indicates that Greece's compliance with the inflation criterion, which was based on its March 2000 inflation performance (as indicated by the vertical line in the figure), hinged on the presence of a sizable negative idiosyncratic inflation shock, as indicated by the $1 \frac{1}{2}$ percentage points difference between headline and common-origin inflations. Indeed, the reduction in headline inflation at that time was attributed to indirect tax cuts, limited adjustments in administered prices, and a series of "gentlemen's agreements" to cap price increases. ${ }^{33}$ However, Greece's commonorigin inflation exhibited a much more gradual downward adjustment during this periodwith the deviation between headline and common-origin inflation attributable to large, serially correlated negative idiosyncratic shocks.

These results suggest that idiosyncratic shocks to inflation can affect a country's ability to satisfy the Maastricht test. This reflects in part the tendency for idiosyncratic shocks to push down the inflation criterion, and is therefore distinct from more traditional concerns related to the incompatibility of the inflation and exchange rate criteria, and the existence of catchup-related inflation. While the difference between the Maastricht criterion and the one based on common-origin inflation has generally been less than $3 / 4$ percentage point, some assessment outcomes - both favorable and unfavorable - have hinged on very small margins (Figure 14). The recent introduction of lower value-added tax rates on services in a number

\footnotetext{
${ }^{31}$ To have operationalized the common-origin inflation concept at that time would have required supplementing HICP data, which has been compiled only since 1996, with historical national consumer price index (CPI) data.

${ }^{32}$ At the time of the euro assessments for the initial eleven entrants (January 1998) and Greece (March 2000), the headline-concept criterion was below the criterion based on common-origin inflation.

${ }^{33}$ See IMF (1999 and 2001).
} 
of EU countries could exacerbate the criterion's downward bias in the near term. ${ }^{34}$ In addition, several EU8 countries - particularly the Baltics - could see sizable positive country-specific price shocks related, inter alia, to the convergence of domestic natural gas prices to world levels and to increases in indirect tax rates to complete tax harmonization. Nevertheless, eliminating the idiosyncratic component from inflation assessments would not be appropriate because it would ignore the influence of business cycles, which, undoubtedly, are not fully synchronized within the EU.

Figure 14. EU11: Average Annual Inflation and Maastricht Criterion (in percent)

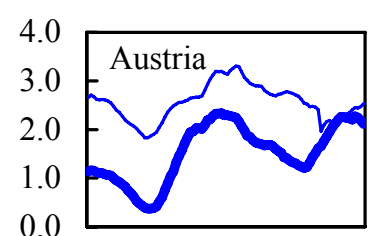

1997M11 2001M3 2004M7
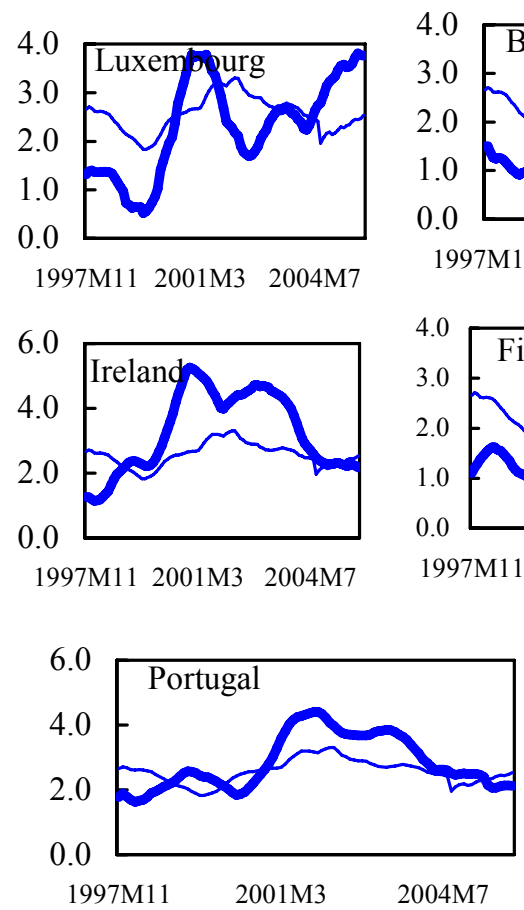
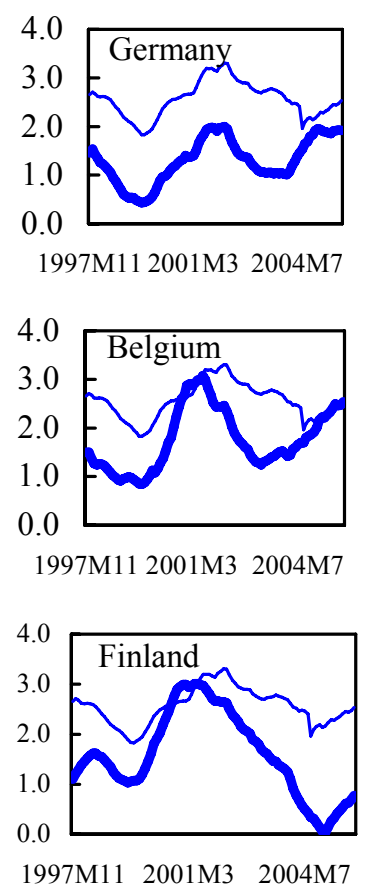
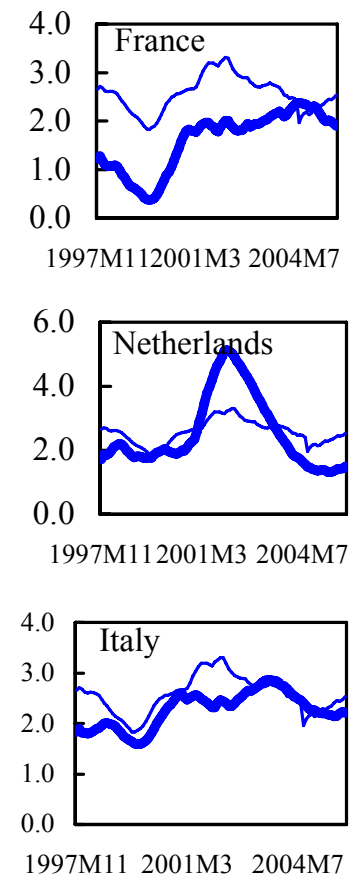

Source: Eurostat; and authors' calculations.

- Average annual inflation

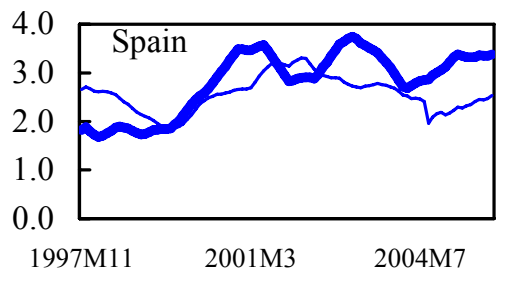

\footnotetext{
${ }^{34}$ From late 2006 through 2010, EU countries were permitted to apply reduced VAT rates on several laborintensive services and on district heat.
} 


\section{CONCLUSIONS AND IMPLICATIONS}

This paper applied a GDFM to partition observed inflation in the EU25 countries into their common-origin and idiosyncratic components. Common-origin inflation is interpreted as headline inflation removed of country- and sector-specific factors. The inclusion of all 25 countries in the analysis is supported by the finding that common shocks account for a similar proportion of observed inflation variability in the EU8 and the EU15. Since the share of inflation variability attributed to common shocks is higher in more open economies (as measured by trade openness with the EU), this suggests that foreign trade is an important channel for propagating price pressures.

Within the EU, cross-country differences in average levels of common-origin inflation are associated with initial price level gaps, movements in nominal effective exchange rates, institutional quality, and economic flexibility. Thus, countries that are richer (and, therefore, have higher price levels), have smaller nominal effective depreciations, more flexible labor markets, or higher-quality legal systems tend to average lower common-origin inflation than other EU members. Improving institutions could sizably reduce inflation, especially in several EU15 countries. With inflation depending on the degree of economic convergenceby nature a gradual process - and characteristics of institutions - which reflect the laws on a country's books as well as their implementation-deviations in common-origin inflation can be expected to display a high degree of persistence.

Country-specific or idiosyncratic inflations, though typically modest, have on occasion substantially affected headline inflation and, therefore, the calculated Maastricht reference inflation rate. Among the EU8, idiosyncratic inflation has tended to track quite closely changes in regulated prices and indirect taxes. Negative country-specific shocks are found to have lowered the calculated level of the Maastricht reference inflation rate, including through the selection of countries that set the criterion. Moreover, a sizable negative own inflation shock allowed Greece to qualify for euro adoption in 2000. This suggests that the inflation criterion may be subject to random noise that could influence assessment outcomes.

The analysis in this paper has several implications for the EU8's ability to comply with the Maastricht inflation criterion. First, cross-country variation in common-origin inflation is heavily influenced by the degree of economic convergence, as reflected in price level gaps. For the EU8 (with the exception of Slovenia, which has relatively high per capita income and price levels), price gaps are among the most important explanations of inflation divergence, pushing up inflation by 1-2 percentage points relative to the EU average and exhausting the $1 \frac{1}{2}$ percentage point buffer afforded by Maastricht. Second, the institutional underpinnings for low inflation are generally present in several of the EU8, suggesting that a culture of stability is already well entrenched in these countries. In general, the EU8 (excluding the Baltics and Slovenia) score highly or very highly on a combined measure of labor market flexibility and legal system quality, outranking many current euro members. This good performance affords them the flexibility to accommodate economic shocks while maintaining low common-origin inflation. Third, the incidence of negative idiosyncratic inflation shocks tends to depress the calculated Maastricht reference rate. In the near term, this effect could be 
relatively large as several countries lower indirect taxes on some services. Moreover, harmonization of indirect taxes and energy price adjustments are still ongoing in the EU8, and these own positive idiosyncratic shocks will push up headline inflation rates. 


\section{REFERENCES}

Aisen, A., and F. Jose Viega, 2005, “ Does Political Instability Lead to Higher inflation? A Panel Data analysis,” IMF Working Paper 05/49 (Washington: International Monetary Fund).

Alesina, Alberto, and Lawrence H. Summers, 1993, "Central Bank Independence and Macroeconomic Performance: Some Comparative Evidence," Journal of Money, Credit, and Banking, Vol. 25, (No. 2), pp. 151-62.

Altissimo, Filippo, Pierpaolo Benigno, and Diego Rodrigues Palenzuela, 2005, "Long-Run Determinants of Inflation Differentials in a Monetary Union," NBER Working Paper No. 11473 (Cambridge, Massachusetts: National Bureau of Economic Research).

Altissimo, Filippo, and others, 2001, "EuroCOIN: A Real Time Coincident Indicator of the Euro Area Business Cycle,” CPER Discussion Paper No. 3108 (London: Centre for Economic Policy Research).

Angeloni, Ignazio, and Michael Ehrmann, 2004, "Euro Area Inflation Differentials," ECB Working Paper No. 388 (Frankfurt: European Central Bank).

Assenmacher-Wesche, Katrin, and Stefan Gerlach, 2006, "Interpreting Euro Area Inflation at High and Low Frequencies," CEPR Discussion Paper No. 5632 (London: Centre for Economic Policy Research).

Bai, Jushan, and Serena Ng, 2002, "Determining the Number of Factors In Approximate Factor Models," Econometrica, Vol. 70 (No. 1), pp. 191-221.

Bofinger, Peter, 1992, “The European Central Bank: Reshaping Monetary Politics in Europe: Discussion" in Establishing a Central Bank: Issues in Europe and lessons from the U.S., pp. 77-80, (Cambridge: Cambridge University Press).

Boreiko, Dimitri, 2002, "EMU and Accession Countries: Fuzzy Cluster Analysis of Membership," Oesterreichische Nationalbank Working Paper No. 71, (Vienna, Oesterreichische Nationalbank).

Borio, Claudio, and Andrew Filardo, 2006, “Globalization and Inflation: New Cross-Country Evidence on the Global Determinants of Domestic Inflation" (unpublished; Basel: Bank for International Settlements).

Bowdler, Christopher; and Luca Nunziata, 2006, "Trade Openness and Inflation Episodes in the OECD," Journal of Money, Credit, and Banking, March 2006, Vol. 38 (No. 2), pp. 553-63. 
Bower, Uwe, and Catherine Guillemineau, 2006, "Determinants of Business Cycle Synchronisation Across Euro Area Countries," European Central Bank Working Paper No. 587 (Frankfurt: European Central Bank).

Bryan, Michael F., and Stephen G. Cecchetti, 1997, "Measuring Core Inflation," in Monetary Policy, Vol. 29, National Bureau of Economic Reseach Studies in Business Cycles (Chicago: University of Chicago Press), pp. 195-215.

Buiter, Willem H., 2005, “The 'Sense and Nonsense of Maastricht' Revisited: What Have We Learnt About Stabilization in EMU?" CEPR Discussion Paper No. 5405 (London: Centre for Economic Policy Research).

Busetti, Fabio, and others, 2006, "Inflation Convergence and Divergence within the European Monetary Union,” ECB Working Paper No. 574 (Frankfurt: European Central Bank).

Collins, Susan M., and Francesco Giavazzi, 1992, "Attitudes Towards Inflation and the Viability of Fixed Exchange Rates: Evidence From the EMS," NBER Working Paper No. W4057 (Cambridge, Massachusetts: National Bureau of Economic Research).

Cristadoro, Riccardo, and others, 2005, "A Core Inflation Index for the Euro Area," Journal of Money, Credit, and Banking, Vol. 37 (No. 3), pp. 539-60.

Cukierman, Alex, 1992, "Central Bank Strategy, Credibility, and Independence: Theory and Evidence," (Cambridge and London: MIT Press).

, and Francesco Lippi, 1999 , "Central Bank Independence, Centralization of Wage Bargaining, Inflation and Unemployment: Theory and Some Evidence," European Economic Review, Vol. 43 (No. 7), pp. 1395-1434.

, Sebastian Edwards; and Guido Tabellini, 1992, "Seigniorage and Political Instability," American Economic Review, Vol. 82 (No. 3), pp. 537-55.

De Broeck, Mark, and Torsten Sløk, 2001, "Interpreting Real Exchange Rate Movements," IMF Working Paper 01/56 (Washington: International Monetary Fund).

De Grauwe, Paul, 2003, Economics of Monetary Union (Oxford, England: Oxford University Press, $5^{\text {th }}$ ed.).

, and Francesco Paolo Mongelli, 2005, "Endogeneities of Optimum Currency AreasWhat Brings Countries Sharing a Single Currency Closer Together?" ECB Working Paper No. 468 (Frankfurt: European Central Bank). 
de Simone, Francisco Nadal, 2005, "Recent French Inflation Behavior: Is It Any Different from the Euro Area's?” in France: Selected Issues, IMF Country Report No. 05/397 (Washington: International Monetary Fund).

European Central Bank, 2003, Inflation Differentials in the Euro Area: Potential Causes and Policy Implications (Frankfurt, Germany: European Central Bank).

European Commission, 2000, European Economy, No. 70: Broad Economic Policy Guidelines: Convergence Report 2000, (Brussels).

, 2006, "European Economy," (Brussels: Office for Official Publications of the EC).

Fabrizio, Stefania; and Ashoka Mody, 2006, "Can Budget Institutions Counteract Political Indiscipline?” Economic Policy, Vol. 21 (No. 48), pp. 689-725.

Fidrmuc, Jarko, and Iikka Korhonen, 2004, “A Meta-Analysis of Business Cycle Correlations between the Euro Area, CEECs and SEECs-What Do We Know?" Focus on European Economic Integration, No. 2/04, (Vienna, Austria: Oesterreichische Nationalbank).

Forni, Mario, and others, 1999, "The Generalized Dynamic Factor Model: Identification and Estimation,” CEPR Discussion Paper No. 2338 (London: Centre for Economic Policy Research).

Forni, Mario, and Marco Lippi, 2001, "The Generalized Dynamic Factor Model: Representation Theory," Economic Theory, Vol. 17 (No. 6), pp. 1113-41.

Geweke, John, 1997, “The Dynamic Factor Analysis of Economic Time Series," in Latent Variables in Socio-Economic Models, ed. by Dennis J. Aigner and Arthur S. Golberger (Amsterdam: North-Holland), Chapter 19.

Hahn, Elke, 2002, "Core Inflation in the Euro Area: An Application of the Generalized Dynamic Factor Model," CFS Working Paper 2002/11 (Frankfurt: Center for Financial Studies).

Hayo, Bernd, 1997, "Eastern European Public Opinion on Economic Issues: Privatization and Transformation," American Journal of Economics and Sociology, Vol. 56 (No. 1), pp. 85-102.

Honohan, Patrick, and Philip Lane, 2003, “Divergent Inflation Rates in EMU," Economic Policy, Vol. 18 (No. 37), pp. 357-94.

International Monetary Fund, 1999, Greece-Staff Report for the 1999 Article IV Consultation, IMF Country Report No. 99/131 (Washington: IMF). 
, 2001, Greece-Staff Report for the 2000 Article IV Consultation, IMF Country Report No. 01/52 (Washington: IMF).

, 2006, "How Has Globalization Affected Inflation?" Chapter III in World Economic Outlook April 2006, (Washington).

Issing, Ottmar, 2006, "Central Bank Independence-Economic and Political Dimensions," National Institute Economic Review, Vol. 196, (No. 1), pp. 66-76.

Kaufmann, Daniel, Aart Kraay, and Massimo Mastruzzi, 2006, "Governance Matters V: Aggregate and Individual Governance Indicators for 1996-2005," World Bank Policy Research Working Paper No. 4012 (Washington: World Bank).

Lane, Philip, 2006, “The Real Effects of EMU," IIIS Discussion Paper No. 115 (Dublin: Institute for International Integration Studies).

Mihaljek, Dubravko, 2002, "The Balassa-Samuelson Effect in Central Europe: A Disaggregated Analysis," paper presented at the Eighth Dubrovnik Economic Conference, Dubrovnik, Croatia.

Morales, Antonia J., and Atilano J. Padilla, "Designing Institutions for International Monetary Policy Coordination," CEPR Discussion Paper No. 1180 (London: Centre for Economic Policy Research).

Przybyla, Marcin, and Moreno Roma, 2005, "Does Product Market Competition Reduce Inflation? Evidence from EU Countries and Sectors," ECB Working Paper No. 453 (Frankfurt: European Central Bank).

Quah, Danny R., and Shaun P. Vahey, 1995, "Measuring Core Inflation," CEPR Discussion Paper No. 1153 (London: Centre for Economic Policy Research).

Reichlin, Lucrezia, 2002, "Factor Models in Large Cross-Sections of Time Series," CEPR Discussion Paper No. 3285 (London: Centre for Economic Policy Research).

Rogoff, Kenneth S., 1985, "Can International Monetary Policy Cooperation Be Counterproductive?” Journal of International Economics, Vol. 18, (Nos. 3-4), pp. 199-217.

Sargent, Thomas J., 1987, Macroeconomic Theory, (Boston: Academic Press, $2^{\text {nd }}$ ed.).

Sargent, Thomas J., and Christopher A. Sims, 1977, "Business Cycle Modelling Without Pretending to Have Too Much A Priori Economic Theory," in New Methods in Business Research, ed. By C.A. Sims (Minneapolis: Federal Reserve Bank of Minneapolis).

Stavrev, Emil, 2006, "Driving Forces of Inflation in New EU Countries," Czech Journal of Economics and Finance, Vol. 56 (Nos. 5-6), pp. 246-57. 
Stock, James H., and Mark H. Watson, 1989, "New Indexes of Coincident and Leading Economic Indicators," NBER Macroeconomics Annual, 1989 (Cambridge, Massachusetts: MIT Press), pp. 351-94.

, 1991, "Testing for Common Trends," in Long Rrun Economic Relationships:

Readings in Cointegration, ed. by R.F. Engle and C.W. Granger (Oxford, England: Oxford University Press), pp. 153-77.

, 2006, "Forecasting With Many Predictors," in Handbook of Economic Forecasting, ed. by G.E. Elliott, C.W. Granger and A. Timmermann (Amsterdam: Elsevier), Chapter 10.

Westaway, P., 2003, "Modeling Shocks and Adjustment Mechanisms in EMU," EMU Study (London: HM Treasury).

World Bank, 2006, Governance Matters IV: Governance Indicators for 1996-2004. Available via the Internet: http://web.worldbank.org/WBSITE/EXTERNAL/WBI/EXTWBIGOVANTCOR/0,,m enuPK:1740542 pagePK:64168427 piPK:64168435 theSitePK:1740530,00.html ,2006, Doing Business. Available via the Internet: http://www.doingbusiness.org/ 


\section{APPENDIX I. IMPLEMENTING THE GDFM}

Estimating the GDFM entails two steps. In the first step, the covariance matrices of the common and idiosyncratic components are derived. To proceed, the number of dynamic common factors, q, must first be determined. This is done by performing principal component analysis on the spectral density matrices of the dataset, calculated for over a grid of frequencies in $[-\pi, \pi]$. The derived eigenvalues represent the share of total data variance explained by the corresponding principal components (eigenvectors) at each frequency, and are in descending order of the amount of variability explained. Determining the number of common factors $q$ is achieved by setting a threshold for the proportion of total variability accounted for by the common factors, and choosing the first $q$ eigenvalues that produce this cumulative variance contribution.

The spectral density matrices of the common components at each frequency are then obtained by pre- and post-multiplying the diagonal matrix of the first $q$ eigenvalues with the matrix of corresponding eigenvectors and its transposed complex conjugate. The estimated spectral density matrices of the idiosyncratic components are then obtained as the difference between the spectral density matrices of the data and the common component. Applying the inverse Fourier transform to these spectral density matrices produces the time-series dimension covariance matrices of the common and idiosyncratic components at all lags.

The second step of the GDFM involves estimating the common components. This is done by "flattening" the $q$ dynamic common factors and their lags into $r=q(s+1)$ separate static factors, where the number of static factors is determined using the panel criterion of Bai and $\mathrm{Ng}$ (2002). The $r$ static factors are obtained by solving the generalized eigenvalue problem involving the covariance matrix of the common component at lag zero, $\Gamma_{\chi}(0)$, weighted by the diagonal matrix of variances of idiosyncratic components, $\Gamma_{\zeta}(0)$. The goal of this procedure is to find the contemporaneous linear combination of the $x_{j t}$ 's which minimize the ratio of the variance of the idiosyncratic and common components. Combining the observed data with the first $r$ generalized eigenvectors (which span the space of the common factors) produces the estimated static factors. Common components are then found by projecting on the $r$ static factors and the covariance matrix of the common components derived in the first step. 


\section{APPENDIX II. DATA DEFINITIONS AND SERIES}

\begin{tabular}{ll}
\hline Dependent variable & \\
\hline Average inflation $\pi_{i}$ & $\left.\begin{array}{l}\mathrm{x}=\text { Average over all months Jan 2002-Dec } 2005 \text { of log(common-origin inflation } \\
\text { index }\end{array}\right)$ - $\log ($ common-origin inflation index $\mathrm{t}-12)$. Common-origin inflation index \\
& $\begin{array}{l}\text { assumes two common factors. Redefines as deviation from the mean by calculating } \mathrm{x} \\
\text { - sample mean. }\end{array}$
\end{tabular}

Independent variables

Relative price level Logarithm of relative price level in 2001, centered around sample mean of 0.

Relative GDP per

capita

Nominal effective

appreciation

Average trade

openness

Logarithm of relative GDP per capita in 2001, centered around sample mean of 0.

Average over all months Jan 2002-Dec 2005 of $\log$ (nominal effective exchange rate ${ }_{t}$ ) nominal effective exchange rate t-12 ). NEER assumes 41 partner countries. Source: Eurostat. Redefined as deviation from the mean by calculating $\mathrm{x}$ - sample mean.

Average import share of GDP

Labor market flexibility

Product market flexibility

Legal quality

Political instability (CNTS)
Average exports and imports 2002-2005 in percent of average GDP 2002-05, centered around sample mean of 0 .

Average imports 2002-2005 in percent of average GDP 2002-05, centered around sample mean of 0 .

First principal component of 9 labor variables from Fraser Institute $(\mathrm{F})$ and World Bank Doing Business (W): Difficulty of hiring (W), difficulty of firing (W), Hiring cost (W), Firing cost (W), Rigidity of employment (W), Rigidity of hours (W), Effective minimum wage (F), Coverage of collective bargaining (F), Hiring and Firing Practices $(\mathrm{F})$. Higher index $=$ greater flexibility. The principal component is centered around zero. Therefore, redefined to be positive with a minimum of 0 by calculating $\mathrm{x}+$ minimum $(\mathrm{x})$. Redefined as sample mean $=1$ by calculating $\mathrm{x} /$ mean $(\mathrm{x})$.

First principal component of 9 competition variables from Fraser Institute (F) and World Bank Doing Business (W): Closing cost (W), years to close (W), recovery value in bankruptcy (W), startup cost (W), startup procedures (W), startup days (W), startup capital (W), administrative barriers to startup (F), survey answers that startup is easy (F). Higher index = greater flexibility. The principal component is centered around zero. Therefore, redefined to be positive with a minimum of 0 by calculating $\mathrm{x}$ + minimum(x). Redefined as sample mean $=1$ by calculating $\mathrm{x} /$ mean $(\mathrm{x})$.

First principal component of 10 legal variables from Fraser Institute $(F)$ and World Bank Doing Business (W):legal procedures (W), legal cost (W), legal days (W), property registration cost $(\mathrm{W})$, property registration procedures $(\mathrm{W})$, property registration days $(\mathrm{W})$, rule of law $(\mathrm{F})$, impartial courts $(\mathrm{F})$, independent judiciary $(\mathrm{F})$, law and order $(\mathrm{F})$. Higher index $=$ better rule of law. The principal component is centered around zero. Therefore, redefined to be positive with a minimum of 0 by calculating $\mathrm{x}+\operatorname{minimum}(\mathrm{x})$. Redefined as sample mean $=1$ by calculating $\mathrm{x} /$ mean $(\mathrm{x})$.

First principal component of 3 measures of political instability from the CrossNational Time Series Database: average number of executive changes 1999-2003, average number of cabinet changes 1999-2003, average number of legislative changes 
1999-2003. Higher index $=$ higher instability. The principal component is centered around zero. Therefore, redefined to be positive with a minimum of 0 by calculating $\mathrm{x}$ $+\operatorname{minimum}(\mathrm{x})$. Redefined as sample mean $=1$ by calculating $\mathrm{x} /$ mean $(\mathrm{x})$.

Political stability (Kaufmann-Kray)
Average 2002-2005, source: Kaufmann and Kray (2006). Redefined to be positive with a minimum of 0 by calculating $\mathrm{x}+\operatorname{minimum}(\mathrm{x})$. Then redefined as sample mean $=1$ by calculating $\mathrm{x} /$ mean $(\mathrm{x})$. 